\title{
Short-chain fatty acids activate acetyltransferase p300
}

Sydney P. Thomas ${ }^{a, b}$, John M. Denu ${ }^{a, b}$

a. Wisconsin Institute for Discovery, 330 N. Orchard Street, Madison, WI, USA; b. Department of Biomolecular Chemistry, University of Wisconsin - Madison, 420 Henry Mall, Madison, WI, USA

Corresponding Author: John M. Denu, john.denu@wisc.edu

\section{Summary Figure}

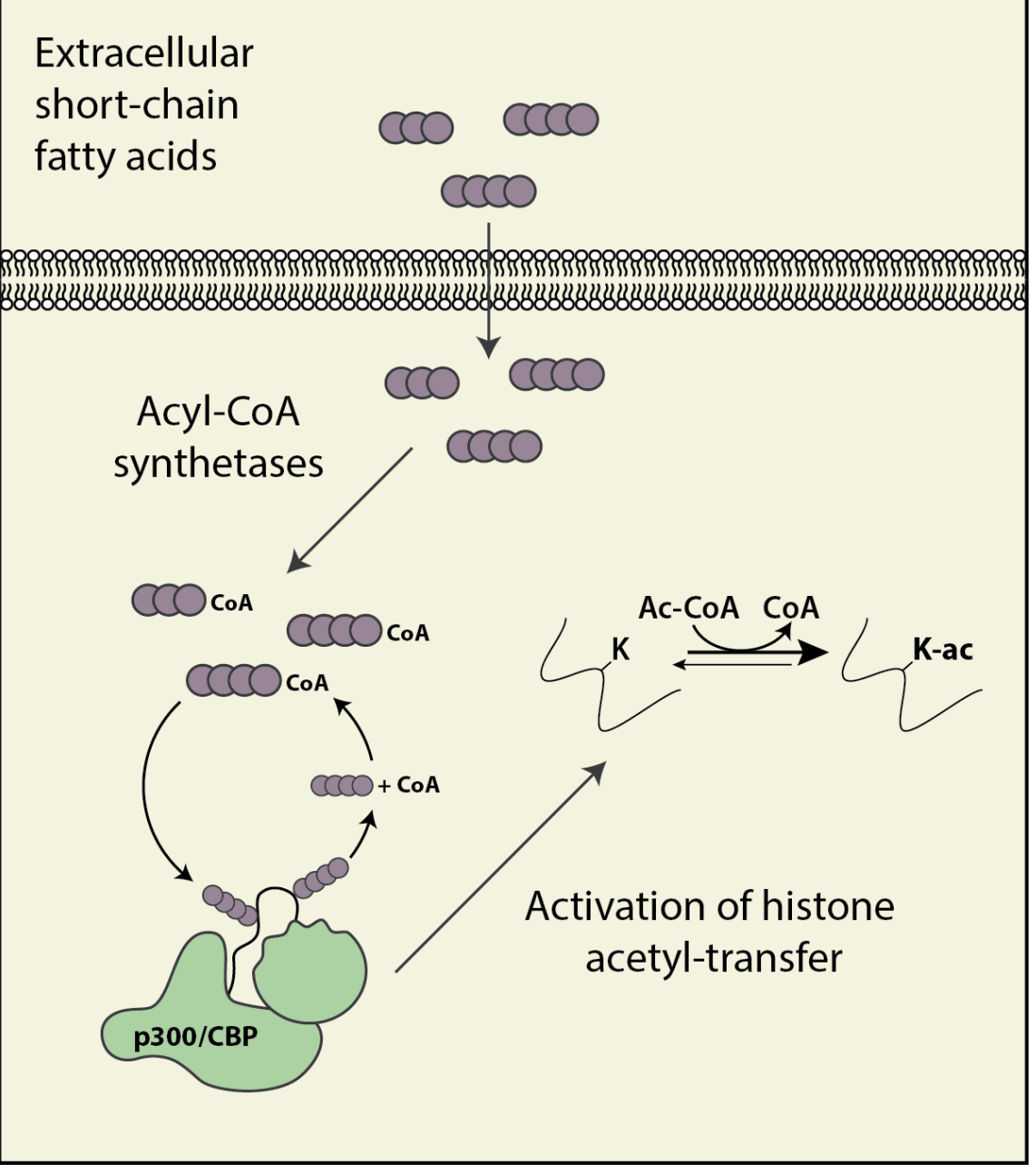

Keywords: short-chain fatty acid, acyl coenzyme A (acyl-CoA), acyltransferase, p300/CBP, bacterial metabolism, fatty acid metabolism 


\section{Abstract}

2 Short-chain fatty acids (SCFAs) acetate, propionate, and butyrate are produced in large quantities by the gut microbiome and contribute to a wide array of physiological processes. While the underlying mechanisms are largely unknown, many effects of SCFAs have been traced to changes in the cell's epigenetic state. Here, we systematically investigate how SCFAs alter the epigenome. Using quantitative proteomics of histone modification states, we identified rapid and sustained increases in histone acetylation after addition of butyrate or propionate, but not acetate. While decades of prior observations would have suggested that hyperacetylation induced by SCFAs are attributed to inhibition of histone deacetylases (HDACs), we found that propionate and butyrate instead activate the acetyltransferase p300. Propionate and butyrate are rapidly converted to the corresponding acyl-CoAs which are then used by p300 to catalyze auto-acylation of the autoinhibitory loop, activating the enzyme for histone/protein acetylation. This data challenges the long-held belief that SCFAs mainly regulate chromatin by inhibiting

14 HDACs, and instead reveals a previously unappreciated mechanism of HAT activation that can explain how even low levels of SCFAs alter global chromatin states.

\section{Introduction}

Short-chain fatty acids (SCFAs) play a crucial role in human health. Although SCFAs include any fatty acid with fewer than six carbons, the first three members of the family - acetate, propionate, and butyrate - are by far the most abundant physiologically (den Besten et al., 2013; Koh et al., 2016; Tan et al., 2014). These three SCFAs are produced in large quantities by bacterial fermentation of nondigestible fiber, and levels can fluctuate based on the amount and type of fiber in the diet (Bird et al., 2000; den Besten et al., 2013; Jenkins et al., 1998; Levrat et al., 1991; Marsono et al., 1993; Ríos-Covián et al., 2016; Velázquez et al., 2000). In

24 humans, total SCFA concentrations can reach over $100 \mathrm{mM}$ in the colon, in a ratio of $\sim 60: 20: 20$ acetate: propionate:butyrate (Cummings et al., 1987; Parada Venegas et al., 2019). SCFAs alone may provide up to $10 \%$ of daily caloric requirements in humans (Bergman, 1990). Colonocytes are especially prone to metabolize SCFAs, deriving $60-70 \%$ of their energy from SCFA oxidation (Roediger, 1982). Excess SCFAs are transported to the liver through the portal vein and are eventually released into the peripheral blood, existing at micromolar concentrations (Bloemen et al., 2009; Cummings et al., 1987).

Butyrate and acetate are the most-studied members of the group. Acetate plays vital roles in cellular metabolism, especially as a building block for the central metabolite acetyl-CoA (Bose et al., 2019; X. Liu et al., 2018; S. Zhao et al., 2016). The physiological effects of butyrate are abundant: butyrate has been reported among other things to improve intestinal barrier function (Chang et al., 2014; Hamer et al., 2008; Peng et al., 2009), reduce inflammation (Chriett et al., 2019; Usami et al., 2008; Vinolo et al., 2011), improve metabolic health (Z. Gao et al., 2009; Lin et al., 2012; Müller et al., 2019), and prevent cancer (Donohoe et al., 2012; Hague et al., 1993). The role of propionate is less clear - while it shows the same beneficial effects as butyrate in many studies, extremely high levels of propionate are associated with negative health outcomes

40 such as propionic acidemia and autism spectrum disorders (Abdelli et al., 2019; Al-Lahham et al., 2010; Li et al., 2017). 
It is generally believed that SCFAs induce physiological effects by changing the cell's epigenetic state (Hamer et al., 2008; Hinnebusch et al., 2002; Krautkramer et al., 2016; Tan et al., 2014). Epigenetics describes the regulation that takes place in eukaryotic chromatin. Much of this regulation centers around histone proteins, which are heavily decorated with post-translational modifications (PTMs). Histone PTMs affect a wide array of processes, from DNA accessibility to transcription factor binding (Bannister \& Kouzarides, 2011; Karch et al., 2013; Kouzarides, 2007). Histone PTMs include lysine acetylation, which opens chromatin and makes it more accessible to transcription, and lysine methylation, which performs various functions. Recently, a host of other histone PTMs have also been identified, including lysine propionylation and butyrylation (Chen et al., 2007a; Dai et al., 2014; Goudarzi et al., 2016; Kebede et al., 2017).

Histone PTMs, as well as the enzymes which add or remove them, are exquisitely sensitive to changes in cellular metabolism (Albaugh et al., 2011; Fan et al., 2015; Sassone-Corsi, 2013). Several central metabolites are also substrates for histone modifications: such as acetyl-CoA, which is used to acetylate histones. Histone acetylation is regulated on two fronts - first by histone acetyltransferases (HATs), which add acetyl-CoA to chromatin, and then by histone deacetylases (HDACs), which remove it (Albaugh et al., 2011). Acetate, propionate, and butyrate have all been reported to inhibit HDACs to varying extents, with butyrate as the most potent inhibitor (Bolduc et al., 2017; Candido et al., 1978; Davie, 2003; Hsu et al., 2016; Silva et al., 2018; Waldecker et al., 2008). HDAC inhibition has been proposed as a mechanism for SCFA's anti-cancer effects (Donohoe et al., 2014; Hinnebusch et al., 2002), insulin regulation (Chriett et al., 2019; Z. Gao et al., 2009), and immunomodulation (Bolduc et al., 2017; Chang et al., 2014; Usami et al., 2008; Vinolo et al., 2011). However, there are still questions as to whether SCFAs regulate the epigenome by HDAC inhibition alone (Corfe, 2012; Donohoe et al., 2012; Gibson, 2000).

It has been recently reported that the gut microbiome can affect histone modifications systemically (Krautkramer et al., 2016; Kumar et al., 2014; Romano et al., 2017; Takahashi et al., 2006; Wellen et al., 2009; S. Zhao et al., 2020). Our lab has demonstrated that germ-free mice display distinct patterns of histone PTMs in multiple tissues (Krautkramer et al., 2016). This phenotype was complex, but could be generally characterized by decreased histone acetylation on multiple sites. However, acetylation levels did not depend solely on bacteria colonized mice fed diets that produced low levels of SCFAs showed similar PTMs to germ-free mice. Finally, simply supplementing germ-free mice with SCFAs in drinking water led to

74 changes in gene expression and histone PTMs that mimicked bacterial colonization. This data strongly suggests that SCFAs are a critical link between the microbiome and epigenetic state. Our understanding of this cross-talk is still in its infancy; thus, discovering how SCFAs interact with host cells on a mechanistic level is crucial to understanding how these systems interact as a whole. Here, we integrate proteomics and metabolomics with biochemical assays to investigate how each SCFA affects epigenetics and cell metabolism. Our results suggest that at 80 physiologic levels, SCFAs induce histone acetylation by activating HATs instead of by inhibiting HDACs. 


\section{Results}

84 Propionate and butyrate induce hyperacetylation in cell culture

To determine the broad effects of extracellular SCFAs on histone PTMs, we treated HCT116 cells with acetate, propionate, and butyrate individually and then performed histone proteomics (Karch et al., 2013; Krautkramer et al., 2015). This mass spectrometry-based method allows for simultaneous analysis of $>70$ histone PTMs, which significantly improves on traditional western blotting (Thomas et al., 2019). While the impact of SCFAs on a few of these PTMs has been studied previously, to our knowledge this is the first study to show how SCFAs regulate a range of both canonical and non-canonical PTMs (Hinnebusch et al., 2002; Kiefer et al., 2006; Silva et al., 2018; Wang et al., 2018). HCT116 cells were initially chosen because they are derived from colon, and colon cells are in most frequent contact with bacterially-produced SCFAs.

94 Propionate and butyrate induced rapid and dose-dependent increases in histone acetylation but did not affect histone methylation (Figure 1A). In contrast, acetate had no significant effect on histone PTMs at any dose or time point tested. These results are consistent with previous reports (Hinnebusch et al., 2002; Kiefer et al., 2006; Silva et al., 2018). The hyperacetylation phenotype with propionate and butyrate was rapid and stable, persisting for at least 24 hours (Figure 1B). We also detected changes in both histone propionylation and butyrylation on

100 multiple sites, including significant increases in K18/K23 propionylation after both propionate and butyrate treatment. In general, changes in histone propionylation and butyrylation were less consistent across experiments compared to the robust changes in histone acetylation, likely due in part to the technical challenges of measuring low-abundance propionylation/butyrylation.

104 Based on these experiments, we chose a standard treatment of $1 \mathrm{mM}$ SCFA for 1 hour, which we used for further experiments unless otherwise indicated. This dose did not affect media $\mathrm{pH}$,

106 media glucose, or cell viability for at least 24 hours (Supplemental Figure 1). The $1 \mathrm{mM}$ dose is within the physiological concentrations in the colon (which range from 0.5-15 mM), but is higher

108 than reported concentrations in other parts of the body (which range from 0-150 $\mu \mathrm{M}$ ) (Cummings et al., 1987; Parada Venegas et al., 2019).

110 To determine whether this effect was unique to HCT116 cells, we also treated three other cell lines derived from diverse human tissues. HEK293, HepG2, and MCF7 cells showed

112 remarkably similar hyperacetylation phenotypes after propionate and butyrate treatment (Figure 1C). Thus, the ability of propionate and butyrate to increase histone acetylation, but not

114 methylation, can be generalized to multiple cell types.

\section{Propionate and butyrate are rapidly metabolized into acyl-CoAs}

116 This experiment raised several intriguing questions. First, what differentiates propionate and butyrate from acetate? It is general knowledge that butyrate can act as an HDAC inhibitor,

118 slowing the removal of acetate from chromatin (Davie, 2003). This could explain the difference between acetate and butyrate, but it does not necessarily explain the difference between

120 acetate and propionate. To test whether propionate could act as an HDAC inhibitor in HCT116 cells, we performed HDAC assays on nuclear extract and determined the apparent $I_{50}$ values 
122 for these SCFAs and their corresponding acyl-CoA forms. Table 1 lists the $\mathrm{IC}_{50}$ values of HDAC inhibition for propionate, butyrate, and corresponding acyl-CoAs. These $\mathrm{IC}_{50}$ values are on the

124 low end of previously-published values, which range from 50-300 $\mu \mathrm{M}$ in nuclear extract and 1-10 mM in whole cells (Huber et al., 2011; Silva et al., 2018; Vinolo et al., 2011; Waldecker et al., 126 2008). While SCFA concentrations in media were theoretically higher than our determined $I_{50}$ values (Figure 2C), it has been previously reported that intracellular concentrations of SCFAs

128 are much lower than extracellular concentrations, which could have bearing on this mechanism (Donohoe et al., 2012).

130 To determine intracellular SCFA concentrations before and after extracellular addition of SCFAs, we treated cells with fully-labeled ${ }^{13} \mathrm{C}$-acetate, propionate, and butyrate and ran

132 targeted LC-MS/MS metabolomics to track SCFAs through cellular metabolism (Figure 2A). After treatment, SCFA concentrations in media declined from $1 \mathrm{mM}$ to $0.5 \mathrm{mM}$ over 24 hours,

134 while SCFA concentrations in cells were consistent and low, ranging between 1-15 $\mu \mathrm{M}$ (Figure 2C). In additional control experiments without cells, SCFA concentrations in media incubated at

$13637^{\circ} \mathrm{C}$ declined at almost an identical rate as that observed in media incubated with cells, suggesting that much of the decrease in media SCFA concentration was due to volatility and not

138 to cellular uptake (Supplemental Figure 2). From this data, we estimated intracellular concentrations of $\sim 40 \mu \mathrm{M}$ of butyrate and $\sim 100 \mu \mathrm{M}$ propionate and acetate, which are

140 consistent with previous results (Donohoe et al., 2012). These values suggest that free SCFAs are rapidly metabolized instead of building up in cells (Boets et al., 2017; Clausen \& Mortensen,

142 1994, 1995). With this in mind, we searched for labeled carbons in downstream TCA cycle metabolites. However, we found no significant labeling of TCA cycle metabolites after

144 propionate and butyrate treatment (Figure 2C). Instead, labeled carbons built up as acylcarnitine species, appearing in as little as 10 minutes and remaining stable for 24 hours (Figure

146 2D). Intriguingly, this build-up did not occur in acetate-treated cells. The same trend occurred in acyl-CoA levels, although these species degrade rapidly and are thus difficult to detect by mass

148 spectrometry (Supplementary Figure 2). Accumulation of acyl-CoAs after SCFA treatment has been previously reported (Basu et al., 2011). In that study, increases in acyl-CoA lead to a

150 decrease of free coenzyme A. Under our conditions, however, free carnitine and free CoA levels did not significantly change (Supplemental Figure 2). To confirm that these metabolic changes

152 were consistent across cell lines, we also performed targeted LC-MS/MS metabolomics in HEK293, HepG2, and MCF7 cells. All cell lines showed the same upregulation of acyl-carnitines

154 after butyrate and propionate treatment (Supplemental Figure 2). Ultimately, these data suggest that histone hyperacetylation may not be due to the presence of intracellular propionate

156 or butyrate, as the intracellular levels of these metabolites are low, but to the presence of propionyl- or butyryl-CoA. Since propionyl- and butyryl-CoA do not inhibit HDAC at physiological concentrations, this raises the possibility that the histone hyperacetylation phenotype may not be due to HDAC inhibition, but to a different mechanism (Table 1) (Vogelauer et al., 2012).

160 The intracellular levels of SCFAs do not support robust HDAC inhibition at micromolar treatment concentrations. However, we and others have measured histone hyperacetylation in response

162 to treatment concentrations as low as $10 \mu \mathrm{M}$ (Supplementary Figure 1) (Biermann et al., 2011; Donohoe et al., 2012; Kespohl et al., 2017). At these concentrations, HDACs would be inhibited $<1 \%$. Alternatively, it has been proposed that hyperacetylation under SCFA treatment is due to 
a direct mechanism, in which acetyl-CoA generated by SCFAs is added directly onto histones (Donohoe et al., 2012). To test whether this occurred in our system, we performed histone proteomics after a 4-hour treatment with ${ }^{13} \mathrm{C}$-labeled SCFAs. This treatment only resulted in 1$5 \%{ }^{13} \mathrm{C}$-labeling on histones, which cannot account for the two or three-fold increases in histone acetylation seen after SCFA treatment (Figure 2B). This indicates that the majority of new acetyl groups ( $90-95 \%)$ were not generated from labeled SCFAs. To confirm that SCFAs do not need to be metabolized into acetyl-CoA to induce hyperacetylation, we knocked down several enzymes involved in acetyl-CoA generation from SCFAs (Figure 2A). siRNA knockdown or genetic knockout of ACLY (an enzyme involved in transport of acetyl-CoA out of the mitochondria), ACSS2 (the cytoplasmic acetyl-CoA ligase), and PCC (an enzyme in the pathway that metabolizes propionyl-CoA to succinyl-CoA) had no significant effect on propionate or butyrate-induced histone acetylation (Supplemental Figure 3). This data indicates that acyl-CoAs are not metabolized to acetyl-CoA in sufficient quantities to explain the induced hyperacetylation, indicating a different mechanism is at play.

\section{Propionyl and butyryl-CoA activate histone acetylation}

180 Next we tested whether the rapidly-formed propionyl- and butyryl-CoA from propionate and butyrate treatment could directly activate HATs (Table 1). Histone acetyltransferase assays 182 demonstrated that propionyl- and butyryl-CoA induced dose-dependent increases in the HAT activity of nuclear extract (Figure 3A). Free propionate and butyrate had no effect. However,

184 since this assay simply measures release of CoA, the apparent increase in HAT activity could have resulted from increased propionyl- or butyryl-transfer reactions. In addition, these results do not indicate which HAT enzymes may be activated.

HATs can be categorized into three main families - GNAT, MYST, and p300/CBP (Albaugh et

188 al., 2011; Berndsen \& Denu, 2008; Fan et al., 2015). Most HATs prefer specific histone lysines and catalyze acetyl-transfer to a handful of histone substrates (Roth et al., 2001). However,

190 p300/CBP acetylates a large number of lysine sites in vitro, and is known to target several of our measured hyperacetylation sites in vivo (Henry et al., 2013). p300/CBP are two closely related

192 transcriptional co-activators - large proteins consisting of several domains and an even larger number of binding partners and acetylation targets (Chan \& Thangue, 2001; Dancy \& Cole,

194 2015; Goodman \& Smolik, 2000). Both proteins encode an autoinhibitory loop (AIL, also called the autoregulatory or activation loop), which must be auto-acetylated to stimulate HAT activity

196 (Karanam et al., 2006; Thompson et al., 2004). Large-scale mass-spectrometry surveys have identified sites of propionylation and butyrylation on p300, including on several AIL lysines;

198 however, how these modifications are added and whether they have a functional consequence on p300 activity are not known (Chen et al., 2007b; Z. Cheng et al., 2009; Kaczmarska et al.,

200 2017). First, we determined whether unmodified p300 can catalyze auto-acylation using propionyl- or butyryl-CoA. Indeed, we found that recombinant p300 performed auto-acylation

202 with propionyl- or butyryl-CoA at rates indistinguishable from auto-acetylation with acetyl-CoA (Figure 3B). Auto-acylation was catalytic, as heat-denatured p300 did not show increases in

204 acylation under the same conditions (Supplemental Figure 4A). Proteomics analysis confirmed the location of propionylation and butyrylation on several AIL lysine sites under these conditions 206 (Table 2). 
Next, we investigated if auto-acylation activates p300 towards histone acetylation. To do so, we compared pre-acylated and unmodified forms of recombinant p300 in radioactive HAT assays to measure acetylation rates on a K18/K23-containing peptide substrate. All forms of acylated p300 (acetylated, propionylated, and butyrylated) were significantly more active than an unmodified control (Figure 3C). In addition, there were no significant differences in the activity

212 of auto-acetylated, propionylated, or butyrylated p300. We confirmed these results by performing western blot HAT activity assays with full-length histone H3/H4 dimers/tetramers,

214 which are a more physiological substrate than a single peptide (Supplementary Figure 4C-D). Again, these data showed an increase in activity for all three forms of acylated p300. In all,

216 these data demonstrate that p300 catalyzes auto-butyrylation and propionylation on AIL sites, and that auto-acylation activates the enzyme in a similar manner to auto-acetylation.

218 To investigate whether this previously unappreciated mechanism functions in vivo, we used pharmacological inhibitors of each potential pathway. To minimize any potential effects from

220 HDAC inhibition in these experiments, we used treatment concentrations from 100-250 $\mu \mathrm{M}$, which should lead to no more than 5-15\% HDAC inhibition (Table 1). First, we treated cells with

222 a potent inhibitor of $\mathrm{p300}, \mathrm{A} 485$. A485 inhibits both histone acetylation and auto-acetylation of p300, and thus should inhibit histone hyperacetylation due to p300 activation (Lasko et al.,

224 2017). Indeed, A485 treatment reversed SCFA-induced hyperacetylation on p300 targets H3K27 and H3K18 (Figure 4A, Supplementary Figure 5A). A485 treatment did not just

226 reverse SCFA-induced hyperacetylation on histone substrates of p300, but also on the nonhistone p300 substrate p53 (K382). Second, we treated cells with the potent HDAC inhibitor,

228 SAHA. Both SAHA and butyrate are thought to be competitive inhibitors of HDACs, although the $I_{50}$ of SAHA is significantly lower $(\sim 10 \mathrm{~nm})$ (Marks \& Breslow, 2007; Sekhavat et al., 2007).

230 Treatment with $10 \mu \mathrm{M}$ of this potent pan-HDAC inhibitor should effectively saturate HDAC inhibition, at least of class I and II HDACs, which are known to target these sites (Caslini et al.,

232 2019; Kelly et al., 2018; Rajan et al., 2018). Thus, if propionate and butyrate act solely as an HDAC inhibitors, they should not induce further hyperacetylation under these conditions.

234 However, $100 \mu \mathrm{M}$ treatment of propionate or butyrate with SAHA still led to significant increases in p53K382 acetylation over a SAHA control (Figure 4A, Supplementary Figure 5A).

236 Collectively, these results suggest that propionate and butyrate induce histone hyperacetylation by an alternative mechanism to HDAC inhibition, likely through the auto-activation of p300 by

238 rapidly-formed acyl-CoAs.

To corroborate this novel mechanism of SCFA action on chromatin, we transfected HCT116 240 cells with two full-length p300 constructs: either wild-type p300 (WT) or an AIL mutant in which 11 of the 17 AlL lysines were mutated to a glutamate ( $\Delta \mathrm{Glu}$ ) (Ortega et al., 2018). The $\Delta \mathrm{Glu}$

242 mutation changes the charge on AIL sites, which in turn blocks auto-acylation of the AIL and prevents p300 activation. As expected, $500 \mu \mathrm{M}$ propionate treatment induced significant

244 increases in histone acetylation after sham and WT transfections (Figure 4B, Supplementary Figure 5B-C). However, cells transfected with the $\Delta$ Glu mutant showed significantly smaller 246 increases in acetylation, approximately half of that seen in WT-transfected cells. In addition, we suspect that even the small increases in acetylation in the $\Delta \mathrm{Glu}$ condition were due to residual 248 amounts of endogenous p300 in transfected cells, or possibly acylation of residual lysine sites 
on the AIL. Nevertheless, these data strongly suggest that the AIL lysines of p300 are necessary to induce the full extent of histone hyperacetylation after propionate treatment.

Lastly, we performed immunoprecipitation of full-length endogenous p300 from HCT116 cells treated with $500 \mu \mathrm{M}$ propionate or butyrate. p300 immunoprecipitated from propionate and butyrate-treated cells showed small but significant increases in activity in a radioactive HAT

254 assay (Figure 4C). Corresponding western blots also identified increased propionylation and butyrylation of p300 under these conditions (Supplemental Figure 5D). In all, our results

256 demonstrate that p300 activation, rather than HDAC inhibition, plays a critical role for propionate and butyrate-induced chromatin hyperacetylation at low concentrations.

\section{Discussion}

For decades, butyrate and propionate's ability to alter chromatin have been attributed to HDAC 260 inhibition (Candido et al., 1978). However, the $\mathrm{IC}_{50}$ values for these two molecules are quite high, with reported values ranging between 50-300 $\mu \mathrm{M}$ in nuclear extract and between 1-10 mM

262 in whole cells (Huber et al., 2011; Silva et al., 2018; Vinolo et al., 2011; Waldecker et al., 2008). While it is possible to reach those concentrations in the gut lumen or portal vein, few other

264 organs would normally reach these values. In addition, our previous data suggests that SCFAs can induce histone hyperacetylation in colon, liver, and adipose tissue, which experience SCFA

266 concentrations that differ by orders of magnitude (Krautkramer et al., 2016). Even in the gut, intracellular concentrations of SCFAs could be significantly lower than exterior concentrations

268 (Donohoe et al., 2012; Sengupta et al., 2006). Thus, the idea that increased histone acetylation is primarily mediated by HDAC inhibition requires re-evaluation.

270 In this study, we report a previously unappreciated mechanism and provide compelling evidence that butyrate and propionate activate p300 at low levels, through the rapid conversion to

272 propionyl-CoA and butyryl-CoA, catalytic auto-acylation, and subsequent activation of p300. While the $\mathrm{IC}_{50}$ values for HDAC inhibition are in the high $\mu \mathrm{M}$ to $\mathrm{mM}$ range, $\mathrm{K}_{\mathrm{m}}$ values for $\mathrm{p} 300$

274 auto-acetylation lie in the $\mathrm{nM}$ to low $\mu \mathrm{M}$ range (Karanam et al., 2006; X. Liu et al., 2008). Hyperacetylation induced by high doses of butyrate $(2-5 \mathrm{mM})$ are almost immediately reversed

276 after butyrate withdrawal (Prasad \& Sinha, 1976; Wang et al., 2018). In contrast, autoacetylation of p300 increases its half-life from 4.5 to $>24$ hours (Jain et al., 2012). Thus, even

278 after extracellular SCFAs have been fully metabolized, modified p300 could still theoretically induce hyperacetylation. Auto-acylation of p300 may thus prove a primary mechanism in

280 physiological systems where SCFA concentrations are low.

It is important to note that acetate had negligible effect on histone acetylation in the cell-based

282 systems described in this paper. Acetate treatment has been previously reported to increase histone acetylation, but only under extreme conditions such as hypoxia (Bulusu et al., 2017; X.

284 Gao et al., 2016), or after genetic manipulation (S. Zhao et al., 2016). Others have reported no effect of acetate in conditions similar to those described here (Hinnebusch et al., 2002). This

286 phenomenon has traditionally been explained by the fact that acetate is a worse HDAC inhibitor than other SCFAs (Hinnebusch et al., 2002; Waldecker et al., 2008). Based on the results

288 reported here, acetate's lack of effect can be explained by the fact that acetate is not rapidly 
metabolized to acetyl-CoA, as propionate and butyrate are to their respective acyl-CoAs. It has been previously shown that extracellular acetate concentration does not necessarily correlate with intracellular concentrations of acetyl-CoA. Instead, under normal conditions, acetyl-CoA is mainly generated in the mitochondria from glucose (Wellen et al., 2009). Since there is no evidence to date of acetyl-CoA crossing the mitochondrial membrane, acetyl-CoA must be

294 shuttled to the cytosol via citrate. Once in the cytosol, citrate is converted into oxaloacetate and acetyl-CoA by ATP citrate lyase (ACLY). However, stress conditions such as hypoxia, or genetic 296 knockout of ACLY, can cause the cell to rely on acetate for acetyl-CoA production (Bulusu et al., 2017; X. Gao et al., 2016; S. Zhao et al., 2016, 2020). We do not expect these conditions to

298 exist in the experiments described here.

300 The main pathways responsible for butyryl-CoA and propionyl-CoA synthesis in the nucleus and cytoplasm are still unclear (Corfe, 2012; Trefely et al., 2020). However, our results suggest that

302 p300 auto-acylation and activation via SCFAs depends on robust cellular synthesis of the corresponding acyl-CoAs. In vivo, synthesis of acyl-CoAs may depend on complex interactions

304 between various SCFAs. While we investigated each SCFA individually, it is possible that mixtures of each SCFA could have varied effects on histone acetylation. However, there is

306 some data to suggest that in cells treated with mixtures of SCFAs, acetylation increased based only on the sum of butyrate and propionate concentrations (Kiefer et al., 2006). This is

308 consistent with our observation that the use of normal or dialyzed FBS in cell culture media did not affect the histone hyperacetylation phenotype (dialyzed FBS does not contain acetate). We

310 predict that rapid histone acetylation, as described for the mechanism revealed in this study, will depend on the ability of cells to convert each SCFA to its corresponding acyl-CoA.

312 The p300 activation mechanism revealed here could also resolve outstanding issues. SCFA treatment phenocopies other HDAC inhibitors in some cases (Chang et al., 2014; Rahman et

314 al., 2003; Zhou et al., 2011), but not others (Milton et al., 2012; Siavoshian et al., 2000; L. Zhao et al., 2020). An alternate method for SCFAs to regulate histone acetylation could account for

316 some of these discrepancies. In addition, several groups have reported that certain phosphatase or PKC inhibitors can reverse SCFA-induced hyperacetylation (Cuisset et al.,

318 1997, 1998; Rickard et al., 1999). While it has been proposed that this is due to phosphorylation of HDACs (Davie, 2003), it is interesting to note that these inhibitors are also known to interact

320 with p300 (H.-H. Cheng et al., 2014; Granja et al., 2008; Zgheib et al., 2012).

Our proposed mechanism also raises the question: why is p300 specifically activated after 322 SCFA treatment? Many HATs can acylate histones, and some are even known to auto-acetylate (Kaczmarska et al., 2017; Leemhuis et al., 2008; Yang et al., 2012). In general, rates of

324 acylation decrease as acyl chains get longer, to the extent that butyryl-CoA can act as a competitive inhibitor for some HATs (Ringel \& Wolberger, 2016; Simithy et al., 2017). Thus, a

326 sharp increase in acyl-CoA concentrations could slow most HATs, which cannot efficiently use longer acyl-CoAs as substrates. Intriguingly, previous reports indicate that p300 is also less

328 efficient at histone propionylation and butyrylation than it is at histone acetylation (Kaczmarska et al., 2017), which is consistent with our histone PTM analyses (Figure 1). However, our

330 measured rates of p300 auto-acylation were indistinguishable between acetate, propionate and butyrate. In addition, the reported $K_{m}$ of p300 for auto-acetylation $(\sim 100 \mathrm{nM})$ is lower than for 
332 acetylation of histone substrates $(\sim 6 \mu \mathrm{M})$ (Karanam et al., 2006; X. Liu et al., 2008). While the differences between the catalytic mechanisms for p300 auto-acylation and histone acylation

334 have not yet been elucidated, this data suggests that p300 may have different substrate preferences for these two reactions. Thus, p300 may prefer to use acyl-CoAs to auto-acylate,

336 which would activate the enzyme towards other substrates targeted for acetylation. In that case, while higher concentrations of acyl-CoAs may slow or inhibit other HATs, they could

338 preferentially activate p300 via auto-acylation. The fact that our proteomics data shows more robust increases in histone acetylation than histone propionylation or butyrylation would further

340 support this hypothesis (Figure 1).

It should be noted that SCFAs are also known to bind and activate several G-protein coupled

342 receptors (GPCRs), especially FFAR2, FFAR3, and HCAR2 (Brown et al., 2003; Inoue et al., 2014; Priyadarshini et al., 2018; Singh et al., 2014; Thangaraju et al., 2009; Xiong et al., 2004).

344 These receptors are not expressed in most of the cell lines investigated here, and do not influence the hyperacetylation phenotype when they are (Figure 1C). However, exploring the

346 potential interactions between GPCR activation and histone hyperacetylation will be critical to a full understanding of SCFA signaling and metabolism, and its impact on human health.

348 The results presented in this study provide key new insight into the actions of normal physiological and therapeutic levels of SCFAs. This is especially important in the case of

350 butyrate, which is the subject of over 100 active clinical trials. In fact, there is already evidence that low SCFA concentrations can have widely different physiological effects while still

352 increasing histone acetylation (Biermann et al., 2011; Donohoe et al., 2012). By comparing cellular responses to high and low SCFA doses (for example, $5 \mathrm{mM}$ and $50 \mu \mathrm{M}$ ), it may be

354 possible to explore distinct cellular responses given the different mechanisms. It may also be necessary to reexamine the systemic effects of SCFAs. Many studies use high doses of SCFAs

356 (5-30 mM), even in regions of the body where physiological concentrations should be thousands of times lower. It is possible that these doses are not necessary to induce hyperacetylation and

358 could in fact obscure biologically-relevant pathways. In the end, this new data suggest that the mechanism of action extends beyond HDAC inhibition and should be incorporated into the

360 rationale for the therapeutic use of SCFAs. 


\section{Methods}

Materials

Cell culture reagents were purchased from Invitrogen (Carlsbad, CA). ACLY, ACSS2, PCC, and non-targeting siRNA pools were purchased from Horizon Discovery (Cambridge, UK). All reagents used for proteomic and metabolomic samples were HPLC-grade. Complete list of 366 antibodies used is available in the Supplementary Data file.

\section{SCFA Cell Line Treatments}

368 All cell lines were plated in Minimum Essential Media (MEM). supplemented with 10\% dialyzed FBS the day before SCFA treatment. MEM contains $\sim 5 \mathrm{mM}$ glucose, compared to $\sim 25 \mathrm{mM}$ in

370 DMEM. Stock solutions of each SCFA were prepared fresh in PBS the day of each experiment. After collection, cell pellets and metabolite extracts were stored at $-80 \mathrm{C}$. Using preliminary data

372 sets to estimate population variance, a minimum of 3 biological replicates are necessary to detect changes of $50 \%$ or greater, assuming $\alpha=0.05$ and power $=0.80$. We thus chose 3-4

374 replicates for all experiments unless otherwise noted.

Histone Proteomics - We performed histone proteomics as described previously (Krautkramer et al., 2016; Sidoli et al., 2016). The method is briefly described below:

Histone extraction and derivatization - Cells were trypsinized and washed once with PBS. Cell pellets were then dounce homogenized in lysis buffer $(10 \mathrm{mM}$ Tris- $\mathrm{HCl}, 10 \mathrm{mM} \mathrm{NaCl}, 3 \mathrm{mM}$ $\left.\mathrm{MgCl}_{2}, \mathrm{pH} 7.4\right)+$ protease inhibitors (10 mM nicotinamide, $1 \mathrm{mM}$ sodium butyrate, $4 \mu \mathrm{M}$

380 trichostatin A, $10 \mu \mathrm{g} / \mathrm{mL}$ leupeptin, $10 \mu \mathrm{g} / \mathrm{mL}$ aprotinin, and $100 \mu \mathrm{M}$ PMSF) and nuclei were spun out. Histones were extracted from the nuclei pellet with $0.4 \mathrm{~N} \mathrm{H}_{2} \mathrm{SO}_{4}$ for 4 hours. Extracted histones were then TCA precipitated overnight and washed with acetone. After performing a Bradford assay to determine protein concentrations, $5 \mu \mathrm{g}$ of each sample was dried down and resuspended in $100 \mathrm{mM}$ triethylammonium bicarbonate buffer. Unmodified lysines were labeled with $\mathrm{d}_{6}$-acetic anhydride, a labeling method that allows for quantification of histone acylations

386 (Thomas et al., 2019). Labeled histones were digested with trypsin and labeled with $\mathrm{N}$-termini phenyl isocyanate before stage tip desalting and resuspension sample diluent $(5 \% \mathrm{ACN}, 0.1 \%$ 388 acetic acid in $\mathrm{H}_{2} \mathrm{O}$ ).

UPLC MS/MS Analysis - Derivatized histone peptide was injected onto a Dionex Ultimate3000 nanoflow HPLC with a Waters nanoAcquity UPLC C18 column (100 m x $150 \mathrm{~mm}, 3 \mathrm{~m})$ coupled to a Thermo Fisher Q-Exactive mass spectrometer at $700 \mathrm{~nL} / \mathrm{min}$. Mobile phase consisted of

392 water $+0.1 \%$ formic acid $(A)$ and acetonitrile $+0.1 \%$ formic acid $(B)$. Histone peptides were resolved with a 2-step linear gradient of $5 \%$ to $35 \%$ B over 45 minutes followed by $35 \%$ to $95 \%$

394 B over 10 minutes. Data was acquired in data-independent acquisition (DIA) mode. The MS1 scan resolution $=35,000$, automatic gain control target $=1 \times 10^{6}$, and scan range $=390-910$

$396 \mathrm{~m} / \mathrm{z}$, followed by a DIA scan with a loop count of 10 . DIA settings: window size $=10 \mathrm{~m} / \mathrm{z}$, resolution $=17,500$, automatic gain control target $=1 \times 10^{6}$, DIA maximum fill time $=$ Auto, and 
398 normalized collision energy $=30$. For each cycle, one full MS1 scan was followed by 10 MS2 scans using an isolation window size of $10 \mathrm{~m} / \mathrm{z}$.

400 Data analysis - Thermo RAW files were loaded into EpiProfile 2.0 and run using the AcD3 module (Yuan et al., 2018). Normalization and statistics were then performed using our

402 previously published Histone Analysis Workflow (Thomas et al., 2019). RAW files, peak tables, and processing scripts have been uploaded to the MassIVE database and can be accessed with

404 username: MSV000087800_reviewer and password: SCFAp300.

\section{Metabolomics}

406 Sample preparation - Cells were plated in 6-well plates and allowed to reach 70\% confluency. Media was replaced with fresh media one hour before the experiment, and then again with

408 media + SCFAs at time 0. Extraction and derivatization solutions were also prepared at least 1 hour before the experiment and stored at -20C. Extraction solution contained 80:20

410 methanol:water with 1:2500 dilution of a heavy amino acid mix standard (MSK-A2, Cambridge Isotope Laboratories); derivatization solution is described below. At each time point, media was

412 collected for SCFA measurements (see below) and cells were washed $3 x$ with $0.9 \% \mathrm{NaCl}$. Then, $700 \mu \mathrm{L}$ of ice-cold extraction solution was added and plates were set at $-80 \mathrm{C}$ for 15

414 minutes. After 15 minutes, cells were scraped into extraction solution and aliquots were taken for SCFA measurement and DNA quantification. The rest was spun down at max speed for 5

416 minutes at 4C. The resulting supernatant was split in two and dried down using a speed vac and stored at -80C. Samples were reconstituted in ice-cold $50 \mathrm{mM}$ ammonium acetate and spun

418 down again before injection into the mass spec. One half of the sample was run in positive mode, while the other half was run in negative mode (details below). Samples were

420 reconstituted in batches and run in random order to minimize error due to metabolite decay or instrumentation.

422 SCFA concentrations were measured by LC-MS using the derivatization protocol described by Lu et. al. (Lu et al., 2013). In brief, $10 \mu \mathrm{L}$ of media or cell extract was added to $150 \mu \mathrm{L}$ of

424 derivatization solution containing $0.5 \mathrm{mM}$ of 2-hydrazinoquinoline, triphenylphosphine, 2,2'dipyridyl disulfide, and either $250 \mu \mathrm{M}$ (for media) or $25 \mu \mathrm{M}$ (for cells) unlabeled acetate, 426 propionate, and butyrate. Samples were incubated at 60C for 1 hour and then spun at max speed for 5 minutes to remove any cellular debris. The resulting supernatant was mixed 1:1 with 428 ice-cold $50 \mathrm{mM}$ ammonium acetate before injection.

To measure cellular concentration, we used the Hoechst staining protocol described by Muschet 430 et. al. (Muschet et al., 2016). To do so, $20 \mu \mathrm{L}$ of metabolite extract was added to $80 \mu \mathrm{L}$ of Hoechst 33342 (CST) diluted to $20 \mu \mathrm{g} / \mathrm{mL}$ in $\mathrm{dd}_{2} \mathrm{O}$. Samples were incubated in the dark for 30

432 minutes in a black 96 -well plate and then read on a plate reader with Ex/Em=355/465 nm. Samples were compared to a dose curve of known cell numbers.

434 UPLC MS/MS Analysis - All metabolites were injected onto a Dionex Ultimate3000 nanoflow HPLC with a Waters ACQUITY UPLC BEH C18 column $(2.1 \mathrm{~mm} \times 100 \mathrm{~mm})$ coupled to a 436 Thermo Fisher Q-Exactive mass spectrometer at $0.2 \mathrm{~mL} / \mathrm{min}$. Separate columns were used for 
positive and negative mode to reduce TBA contamination. For samples run in positive mode, mobile phase consisted of water $+5 \mathrm{mM}$ ammonium acetate $+0.05 \%$ acetic acid $(\mathrm{A})$ and $90 \%$ acetonitrile $+5 \mathrm{mM}$ ammonium acetate $+0.05 \%$ acetic acid $(\mathrm{B})$. Positive mode metabolites were resolved with a two-step linear gradient of $2 \%$ to $85 \%$ B over 5 minutes followed by $85 \%$ to $95 \%$ B over 6 minutes. For derivatized samples, data was acquired in data-dependent acquisition

442 (DDA) mode. MS1 scan resolution = 140,000, automatic gain control target $=3 \times 10^{6}$, and scan range $=189-450 \mathrm{~m} / \mathrm{z}$. MS2 scan resolution $=35,000$, automatic gain control target $=1 \times 10^{5}$, loop

444 count $=5$, and isolation window $=4.0 \mathrm{~m} / \mathrm{z}$. For other positive mode samples, only MS1 data was acquired in two isolation windows from $60-184 \mathrm{~m} / \mathrm{z}$ and $189-1200 \mathrm{~m} / \mathrm{z}$. MS1 scan resolution $=$

44670,000 , automatic gain control target $=1 \times 10^{6}$.

For samples run in negative mode, mobile phase consisted of methanol $(A)$ and water $+3 \%$ 448 methanol $+10 \mathrm{mM}$ tributylamine $+0.05 \%$ acetic acid $(\mathrm{B})$. Metabolites were resolved with a linear gradient of $95 \%$ to $5 \%$ B over 15 minutes. Only MS1 data was acquired. Scan resolution

$450=70,000$, automatic gain control target $=1 \times 10^{6}$, and scan range $=59-880 \mathrm{~m} / \mathrm{z}$.

Data analysis - Metabolite identification and peak integration was performed in EL-MAVEN

452 (Elucidata). For SCFA concentrations, heavy SCFAs were normalized to unlabeled internal controls and SCFA dose curves run throughout the course of the experiment. For all other

454 metabolites, data was normalized to heavy amino acid standards and cell number determined by Hoechst stain. All ${ }^{13} \mathrm{C}$-labeling was corrected based on natural ${ }^{13} \mathrm{C}$ abundance.

ACLY, ACSS2, and PCC knockdowns

HCT116 cells were transfected with siRNA SMARTpools targeting ACLY, ACSS2, and PCC

458 according to manufacturer protocols. In short, $10 \mathrm{nM} \mathrm{ACLY,} \mathrm{ACSS2,} \mathrm{and} \mathrm{non-targeting} \mathrm{siRNAs}$ and $20 \mathrm{nM}$ PCC siRNA were transfected using Lipofectamine RNAiMAX and opti-MEM media

460 and allowed to incubate for 48 hours. Media was then replaced with fresh MEM media containing $1 \mathrm{mM}$ SCFA and incubated for 1 hour. Knockdown efficiency was assessed by 462 western blotting.

Primary lymphoblasts from patients with propionic acidemia and family-matched controls were 464 purchased from the NIGMS Human Genetic Cell Repository. Propionic acidemia is a rare genetic disease caused by mutations in PCC. Knockout of PCC activity was confirmed using the

466 HPLC assay developed by Liu et. al. (Y.-N. Liu et al., 2016). Since lymphoblasts are grown in suspension, stock solutions of SCFA were added directly to media, resulting in $1 \mathrm{mM}$ final

468 concentrations. Cells were treated with SCFAs for 4 hours before collection.

HDAC Assay

470 HDAC activity of HCT116 nuclear extract was assayed using the Fluorometric HDAC Activity Assay kit from Abcam (ab156064) according to manufacturer protocol. Briefly, nuclear extract

472 was prepared by dounce homogenizing cell pellets in lysis buffer $(10 \mathrm{mM}$ Tris- $\mathrm{HCl}, 10 \mathrm{mM} \mathrm{NaCl}$, $3 \mathrm{mM} \mathrm{MgCl}_{2}, \mathrm{pH}$ 7.4), then spinning out nuclei and resuspending in nuclear extraction buffer (50 $474 \mathrm{mM}$ HEPES, $420 \mathrm{mM} \mathrm{NaCl}, 0.5 \mathrm{mM}$ EDTA, $0.1 \mathrm{mM}$ EGTA, 10\% glycerol, pH 7.5). Protein 
concentration was determined by Bradford, and then $50 \mu \mathrm{g}$ was added to dose curves of

476 butyrate, propionate, and their corresponding acyl-CoAs. TSA was used as a positive control. Fluorescence signal $(E x / E m=360 / 450 \mathrm{~nm})$ was read on a plate reader at 2 minute intervals for 1

478 hour. Values were averaged over two technical replicates. $I_{50}$ values were calculated using GraphPad Prism.

\section{HAT Assays}

Colorimetric Assay - HAT activity was assayed using the HAT Activity Assay Kit from Sigma

482 (EPI001), which measures release of free CoA over time. Acetyl-CoA levels were kept constant at $100 \mu \mathrm{M}$. Nuclear extract was the same as that used in the HDAC assay. $50 \mu \mathrm{g}$ nuclear

484 extract was added to kit components and dose curves of butyrate, propionate, and corresponding acyl-CoAs. Signal at $440 \mathrm{~nm}$ was read on a plate reader at 2 minute intervals for

4862 hours. Values are averaged over two technical replicates.

Recombinant p300 - Recombinant catalytic domain of p300 was purchased from Enzo Life

488 Sciences (BML-SE451). To remove endogenous acetylation from the recombinant protein, p300 was incubated with mammalian SIRT2 and NAD. SIRT2 was kindly provided by Dr. Mark Klein.

490 For each experiment, equimolar amounts of SIRT2 and p300 and a 10 fold molar excess of NAD were incubated at RT for 45 minutes. This incubation reduced endogenous acetylation on

492 p300 5-10 fold without inhibiting auto-acylation (Supplemental Figure 4B). Excess NAD was then removed by running protein over a Zeba Spin desalting column (ThermoFisher). Acyl-CoAs

494 were then added back to the enzyme and auto-acylation allowed to continue at RT for 30-60 minutes. For untreated controls, the same amount of CoA was added to account for CoA

496 concentration. Lastly, for denatured samples, p300 was incubated with SIRT2 and then boiled at 95C for 5 minutes before addition of acyl-CoAs.

498 Auto-acylation assay - Recombinant enzyme was treated with SIRT2, then diluted to $1 \mu \mathrm{M}$ in HAT assay buffer (50 mM BIS-TRIS, $25 \mathrm{mM}$ TRIS, $10 \mathrm{mM} \mathrm{NaCl}, \mathrm{pH}$ 7) with $80 \mu \mathrm{M}$ acyl-CoA.

500 For each time point, $2 \mathrm{uL}$ of each sample was dotted directly onto nitrocellulose membrane. Membranes were then allowed to dry for 30 minutes before blocking and incubating with 502 antibodies specific to each acyl-CoA.

Identification of lysine acylation - Recombinant enzyme was prepared as described above, then

504 dried down, resuspended in $100 \mathrm{mM}$ triethylammonium bicarbonate buffer and trypsinized overnight. Samples were then stage tip desalted and resuspended in sample diluent (same as

506 histone protocol above). Samples were run on a Thermo Fisher Q-Exactive mass spectrometer using the same settings as histone samples, except that they were run in DDA rather than DIA

508 mode. Acyl identification was performed using Mascot (Matrix Science) and manually validated in XCalibur (ThermoFisher). Acylation had to be present in 2 of 3 samples to be reported.

$510{ }^{3} \mathrm{H}$ acetylation assay - Tritiated acetyl-CoA was purchased from PerkinElmer. For each assay, reaction buffer was made by using HAT assay buffer with $5 \mu \mathrm{M}$ cold acetyl-CoA, $1 \mu \mathrm{M}$ hot

512 acetyl-CoA, and $25 \mu \mathrm{M}$ biotinylated peptide. Biotinylated peptide was kindly provided by $\mathrm{Dr}$. Vyacheslav Kuznetsov and corresponds to resides 9-23 of histone H3. Reactions were started 
514 by addition of $24 \mu \mathrm{L}$ reaction buffer to $2 \mu \mathrm{L}$ acetylated p300 (final concentration $10 \mathrm{nM}$ ). At each time point, $7 \mu \mathrm{L}$ of the reaction mixture was added to $150 \mu \mathrm{L}$ of cold $2 \%$ TFA $+5 \%$ Streptavidin

516 Sepharose High Performance (v/v, Cytiva). After the time course was completed, samples were incubated at RT with shaking for 30 minutes. The samples were then spun down at $1000 \mathrm{xg}$ for

5181 minute, and then washed with $2 \mathrm{~mL}$ of $10 \%$ acetone. The washed sepharose was then directly added to $2 \mathrm{~mL}$ Ultima Gold ${ }^{\mathrm{TM}}$ scintillation cocktail (PerkinElmer). Radioactivity was read by a Tri-

520 Carb 2910TR scintillation counter (PerkinElmer). The scintillation counter was calibrated before each run.

522 Western HAT assays - For western samples, $100 \mathrm{nM}$ acylated p300 was added to a master mix of $100 \mu \mathrm{L}$ acetyl-CoA and $0.4 \mu \mathrm{g} / \mu \mathrm{L}$ histone $\mathrm{H} 3 / \mathrm{H} 4$ dimers. Samples were collected by adding

$52420 \mu \mathrm{L}$ directly to $5 \mu \mathrm{L}$ of $4 \mathrm{X}$ sample loading buffer (LI-COR) and heating at 95C for 5 minutes. Samples were run on Bolt 4-12\% Bis-Tris gels using the XCell II blot module (ThermoFisher).

526 Protein was transferred onto nitrocellulose membranes for 45 minutes and then allowed to block in 5\% BSA for 1 hour. Samples were incubated in primary antibody overnight, before washing 528 and incubating in LI-COR secondary antibody for 1 hour. All membranes were imaged on a LICOR Odyssey imager and quantified using ImageStudio (LI-COR). Whenever possible,

530 antibodies for modifications and loading controls were run simultaneously using two separate fluorescent LI-COR channels.

532 p300 transfections - p300 plasmids were a kind gift from Dr. Daniel Panne (Ortega et al., 2018) HCT116 cells were grown to $\sim 60 \%$ confluency and transfected with Lipofectamine 3000

534 according to manufacturer protocols. After 48 hours, media was replaced with MEM media containing $500 \mu \mathrm{g} / \mathrm{mL}$ Geneticin (ThermoFisher). Antibiotic media was then replaced every two

536 days for one week to select for transfected cells. After one week, cells were treated with $500 \mu \mathrm{M}$ propionate for 2 hours. Samples were collected as described previously. HA and p300 blots

538 were performed as described in the previous section, except that transfers were allowed to run overnight to maximize signal for high molecular weight proteins.

540 p300 immunoprecipitation - HCT116 cells were grown to 60-70\% confluency and treated with $500 \mu \mathrm{M}$ propionate or butyrate for 1 hour. Cells were lysed using RIPA buffer and Pierce

542 protease phosphatase inhibitors (ThermoFisher). Protein concentrations were determined by Bradford assay and equal amounts of protein were added to a slurry of Dynabeads Protein G

544 (ThermoFisher) and p300 antibody (NM11, Santa Cruz Biotechnology). Samples were allowed to incubate 3 hours at $4 \mathrm{C}$ before washing twice with Tris buffer $+0.01 \%$ Triton. Washed beads

546 were then directly added to radioactive assays or run on gels as described previously. For radioactive assays, beads were incubated with $1 \mu \mathrm{M}$ hot acetyl-CoA and $25 \mu \mathrm{M}$ biotinylated

548 peptide for 1 hour before quenching reaction in 2\% TFA + 5\% Streptavidin Sepharose High Performance (v/v, Cytiva).

\section{Acknowledgements}

p300 plasmids were a kind gift from Dr. Daniel Panne, Leicester Institute of Structural and 552 Chemical Biology, UK. Pan-butyryl antibody was the kind gift of Dr. Yingming Zhao, University of Chicago, USA. Recombinant SIRT2 was kindly provided by Dr. Mark Klein. H3 and H4 
bioRxiv preprint doi: https://doi.org/10.1101/2021.07.21.453192; this version posted July 21, 2021. The copyright holder for this preprint (which

was not certified by peer review) is the author/funder, who has granted bioRxiv a license to display the preprint in perpetuity. It is made available under aCC-BY 4.0 International license.

554 proteins and peptides were kindly provided by Dr. Vyacheslav Kuznetsov, Dr. Wallace Liu, and Lily Miller. We thank Dr. James Dowell and Eric Armstrong for their helpful discussions of mass

556 spec analysis. We also thank Dr. Mark Klein, Jose Moran, and Dr. Spencer Haws for their helpful discussions of HAT assays.

\section{Conflict of Interest}

The authors declare that they have no conflicts of interest with the contents of this article. 
bioRxiv preprint doi: https://doi.org/10.1101/2021.07.21.453192; this version posted July 21, 2021. The copyright holder for this preprint (which was not certified by peer review) is the author/funder, who has granted bioRxiv a license to display the preprint in perpetuity. It is made available under aCC-BY 4.0 International license.

Table 1: IC 50 of HDAC inhibition for SCFAs and acyl-CoAs

\begin{tabular}{|l|c|}
\hline Molecule & IC $_{50}$ \\
\hline Propionate & $223 \pm 64 \mu \mathrm{M}$ \\
\hline Butyrate & $52 \pm 11 \mu \mathrm{M}$ \\
\hline Propionyl-CoA & $18 \pm 7 \mathrm{mM}$ \\
\hline Butyryl-CoA & $1.13 \pm 0.01 \mathrm{mM}$ \\
\hline
\end{tabular}

Table 1: IC 50 values of HDAC inhibition for propionate, butyrate, propionyl-CoA, and butyrylCoA. Values are calculated from dose curves using $n=2$ technical replicates, raw data can be found in the Supplementary Data file. 
Table 2: Sites of p300 acylation

\begin{tabular}{|l|c|c|c|}
\hline $\begin{array}{l}\text { Lysine Site } \\
\text { (AlL lysines in bold). }\end{array}$ & Acetylation & Propionylation & Butyrylation \\
\hline K1516 & A & P & \\
\hline K1520 & A & P & \\
\hline K1523 & A & & \\
\hline K1524 & A & P & \\
\hline K1525 & A & P & B \\
\hline K1528 & A & P \\
\hline K1529 & A & P & B \\
\hline K1532 & A & P & B \\
\hline K1534 & A & P & \\
\hline K1542 & A & P & \\
\hline K1543 & A & P & \\
\hline K1544 & A & A & \\
\hline K1558 & A & & \\
\hline K1564 & & & \\
\hline K1611 & A & & \\
\hline
\end{tabular}

Table 2: Sites of lysine acetylation, propionylation, and butyrylation on recombinant p300 treated with acyl-CoAs. AlL: autoinhibitory loop, A: acetylation, P: propionylation, B: butyrylation. 
Figure 1: Extracellular propionate and butyrate induce histone hyperacetylation
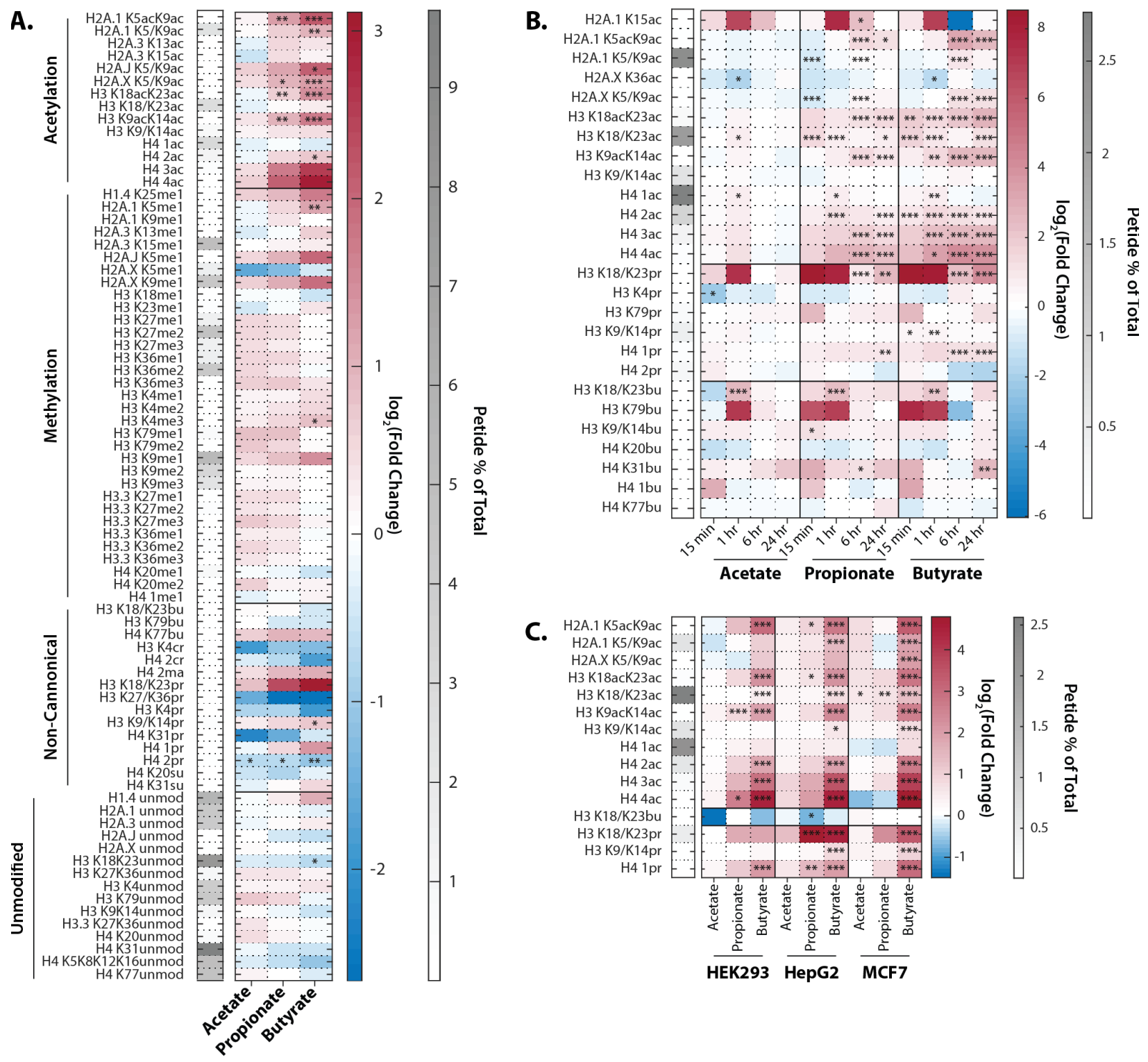

Figure 1: A. Histone proteomics of HCT116 cells treated with $1 \mathrm{mM}$ acetate, propionate, or butyrate for 1 hour. B. Histone acylation over a time course of $1 \mathrm{mM}$ acetate, propionate, or butyrate treatment C. SCFA treatment (1mM, 1 hour). of HEK293, MCF7, and HepG2 cell lines. All values are $\log _{2}$ (Fold Change) over untreated, time-matched controls. ${ }^{*}=p \leq 0.05,{ }^{* *}=p \leq 0.01$, $* * *=p \leq 0.001 . n=3$ per condition. 
Figure 2: Metabolism of extracellular short-chain fatty acids
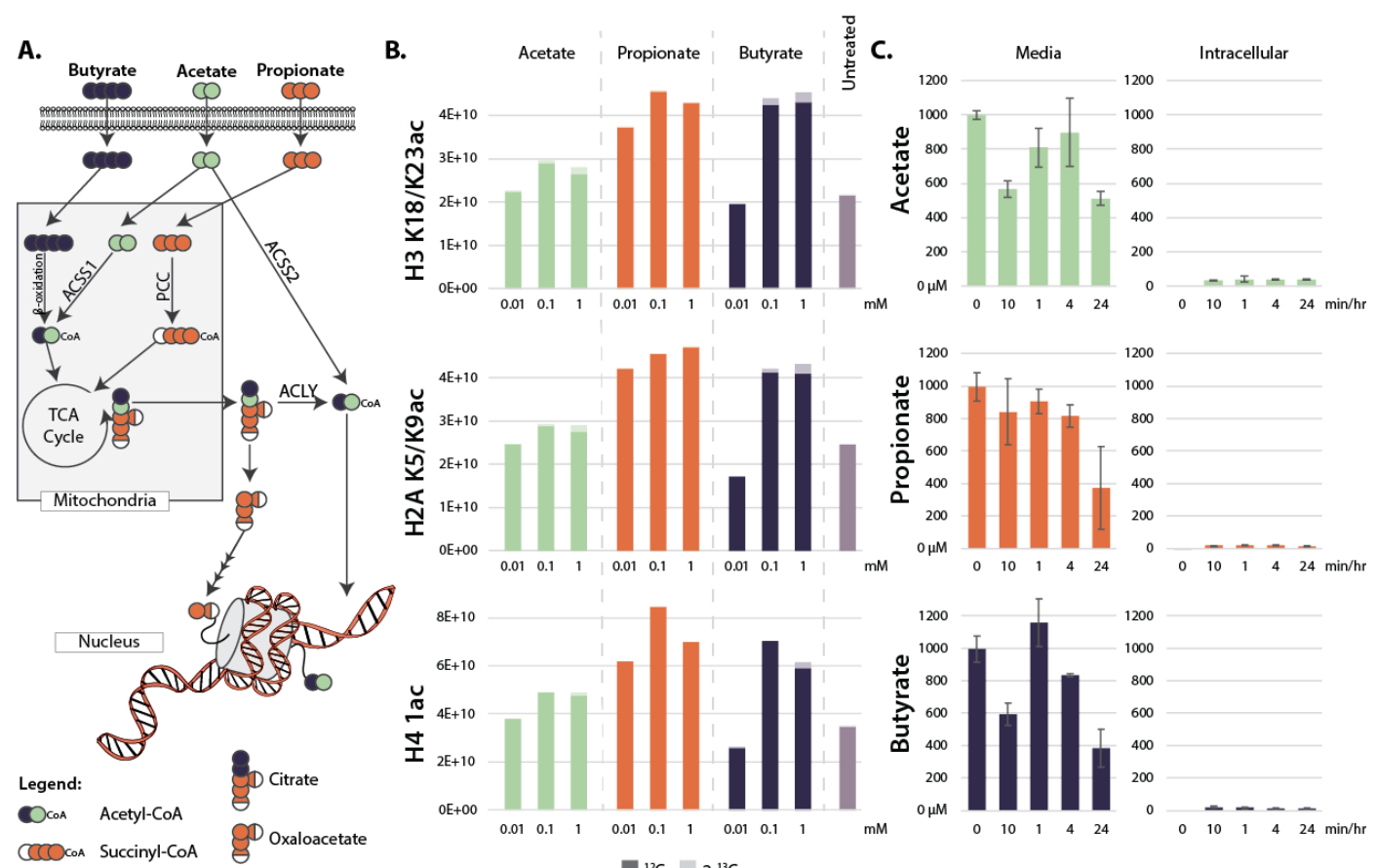

D.

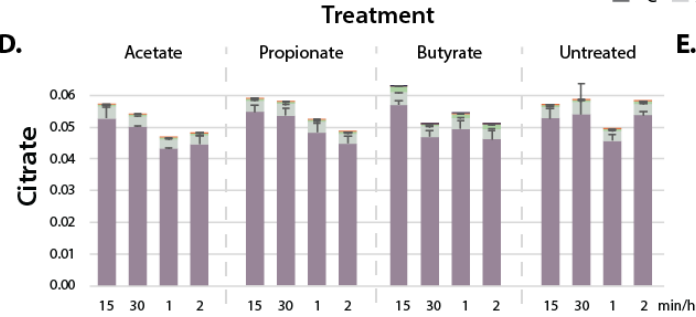

E.

Treatment
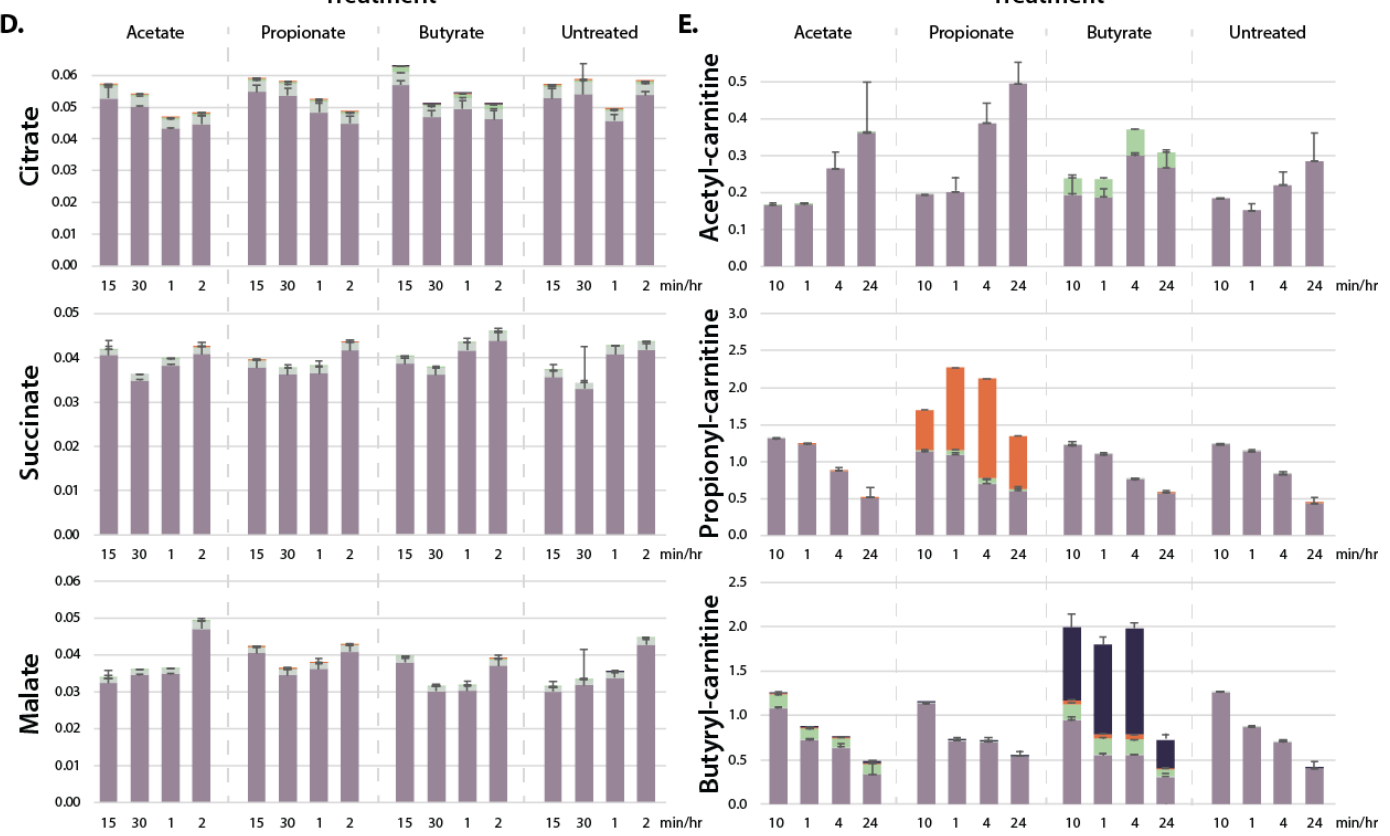

$=C_{12}=1-C_{13}=2-C_{13}=3-C_{13}=4-C_{13}$

Figure 2: A. Overall scheme of SCFA metabolism. B. Proportion of ${ }^{13} \mathrm{C}$ on histones after 4hour treatment with labeled SCFAs C. LC-MS concentration of SCFAs in media and in cells over a 24 hour time course D-E. ${ }^{13} \mathrm{C}$ labeling of TCA cycle metabolites (D) and acyl-carnitines (E) over a 24 hour time course. Values are average and standard deviation of normalized signal intensity of $\geq 3$ biological replicates. 
Figure 3: Acyl-CoAs activate p300

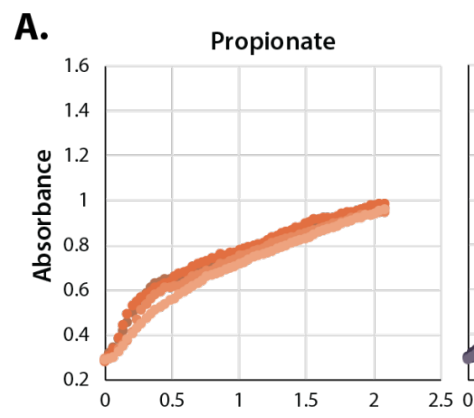

B.

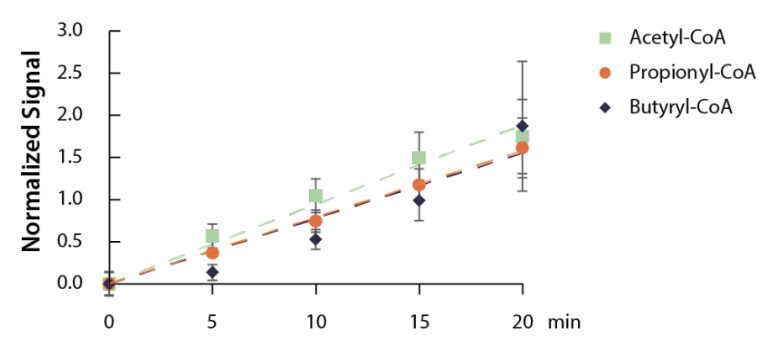

Butyrate

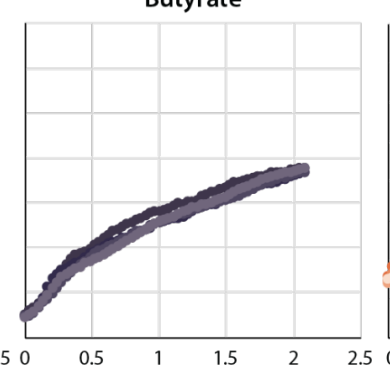

Propionyl-CoA

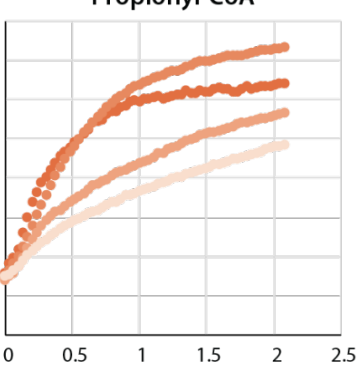

Butyryl-CoA

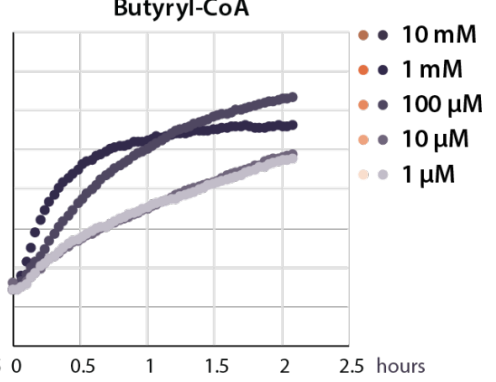

C.

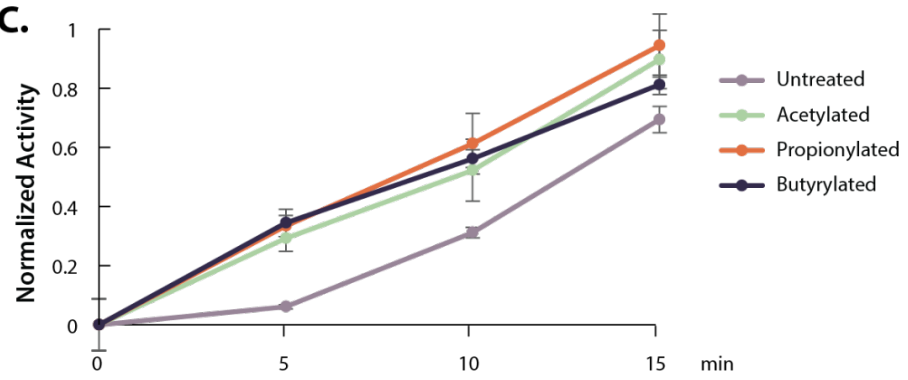

Figure 3: A. HAT activity of nuclear extract treated with a dose curve of SCFAs and acyl-CoAs B. Rate of p300 auto-acylation with acetyl-CoA, propionyl-CoA and butyryl-CoA. Values are average and standard deviation, $n=4$ per condition. C. Rate of histone acetylation by acetylated, propionylated, or butyrylated p300 using radioactive acetyl-CoA. Values are average and standard deviation, $n=3$ per condition. Replicate results from this assay performed with different enzyme preparations on different days are shown in Supplemental Figure 4. Quantification for all replicates including western blots and radioactive assays available in the Supplementary Data file. 
Figure 4: p300 inhibition, but not HDAC inhibition, reverses SCFA-induced hyperacetylation

A.

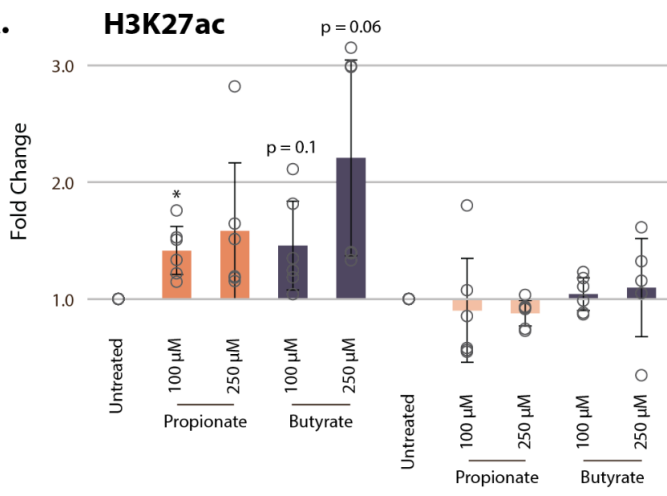

H3K18ac
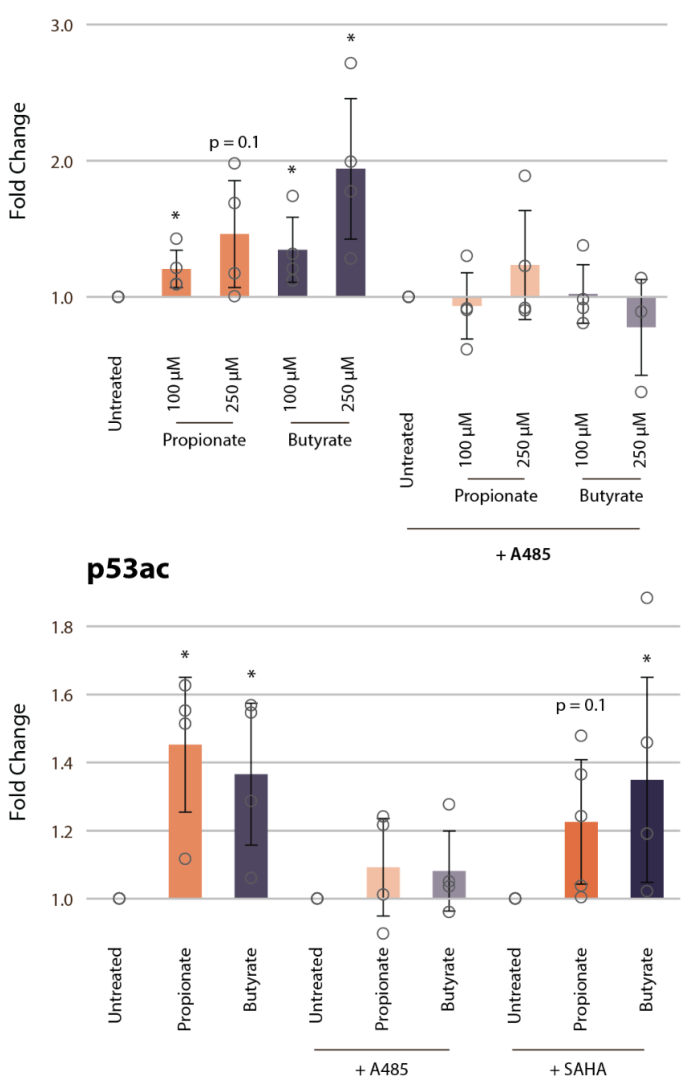

B. H3K27ac

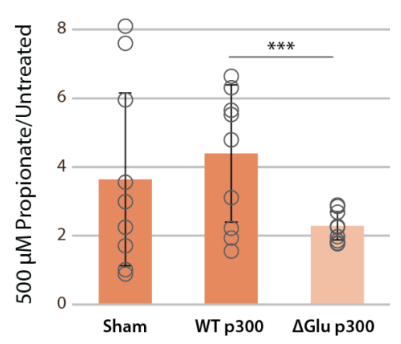

H3K18ac

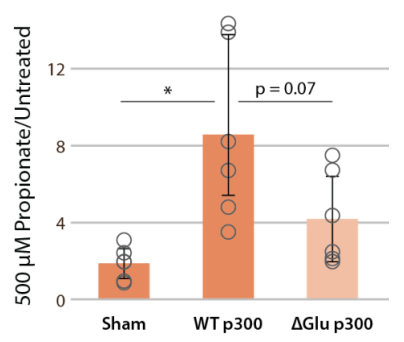

C.

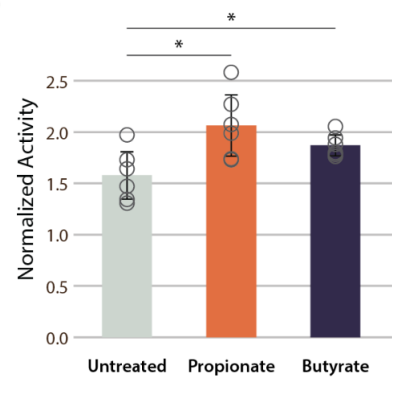

Figure 4: A. Acetylation of H3K27ac, H3K18ac, and p53K382ac after treatment with A485, SAHA, and 100-250 $\mu \mathrm{M}$ of propionate/butyrate for 24 hours. Values are normalized to total $\mathrm{H} 3$ or total p53 before calculating fold changes to the appropriate untreated control. B. Acetylation of H3K27ac and H3K18ac in cells transfected with sham, WT p300, or $\Delta$ Glu p300 plasmids. C. Activity of immunoprecipitated p300 after treatment with $500 \mu \mathrm{M}$ of propionate or butyrate. Activity is measured with a radioactive assay and normalized to concentration of immunoprecipitated p300 in each sample. ${ }^{*}=p \leq 0.05,{ }^{* *}=p \leq 0.01,{ }^{* * *}=p \leq 0.001 . n \geq 3$ per condition. 
Supplemental Figure 1: Physiological effects of SCFA treatment
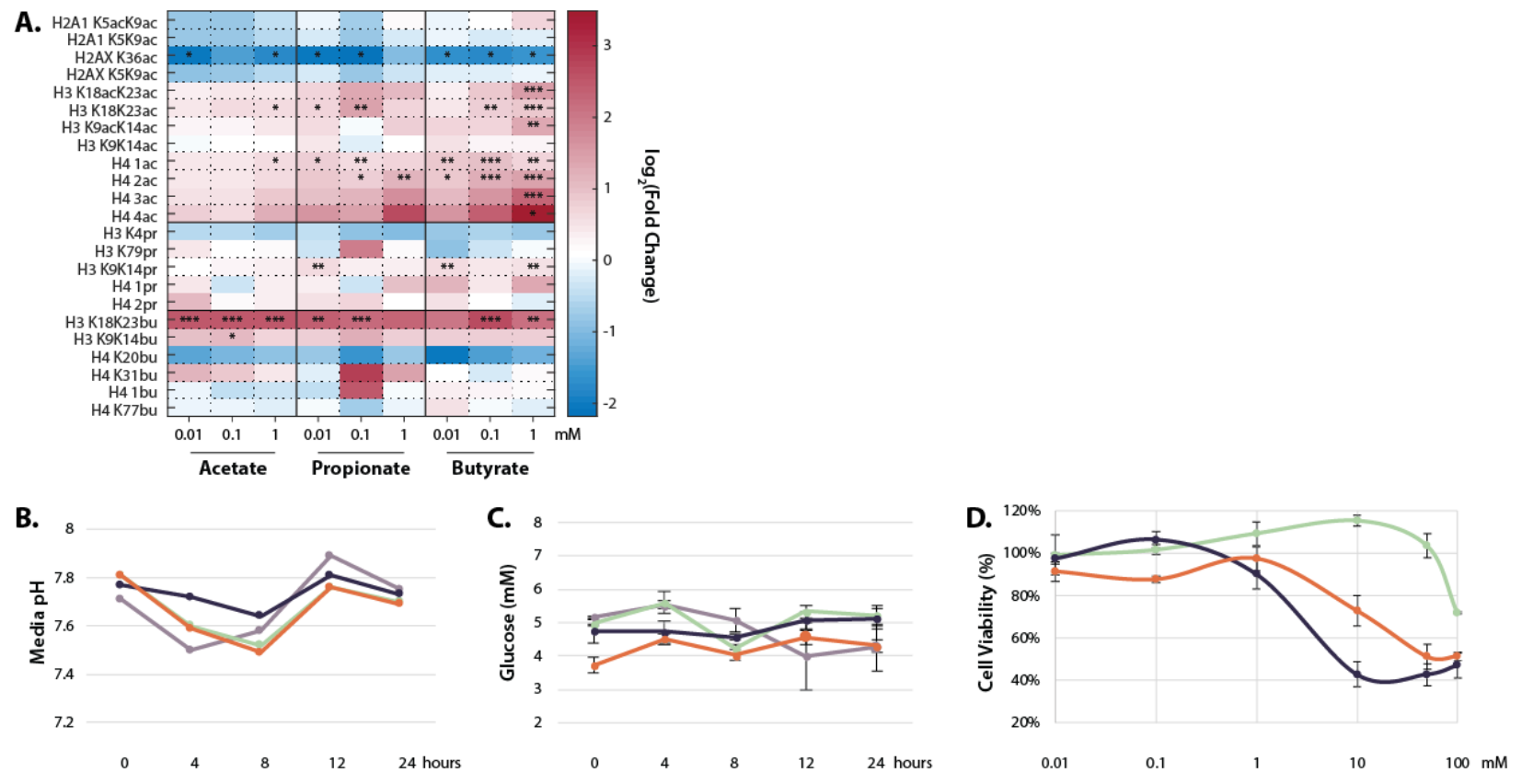

$\rightarrow$ Untreated $\rightarrow$ Acetate $\rightarrow$ Butyrate $\rightarrow$ Propionate

Supplemental Figure 1: A. Histone proteomics of HCT116 cells treated with $0.01,0.1$, or $1 \mathrm{mM}$ acetate, propionate, or butyrate for 1 hour. Values are $\log _{2}$ (Fold Change) over untreated control. ${ }^{*}=p \leq 0.05,{ }^{* *}=p \leq 0.01,{ }^{* * *}=p \leq 0.001$ B. Media pH of HCT116 cells over 24 SCFA treatment $\mathbf{C}$. Media glucose concentration over 24 hour SCFA treatment D. Cytotoxicity curves for acetate, propionate, and butyrate after 24 hour treatment. All experiments were repeated at least twice with an $n=3$ per condition, representative data is shown. Raw values for $B-D$ can be found in the Supplementary Data file. 
Supplemental Figure 2: Further SCFA metabolism
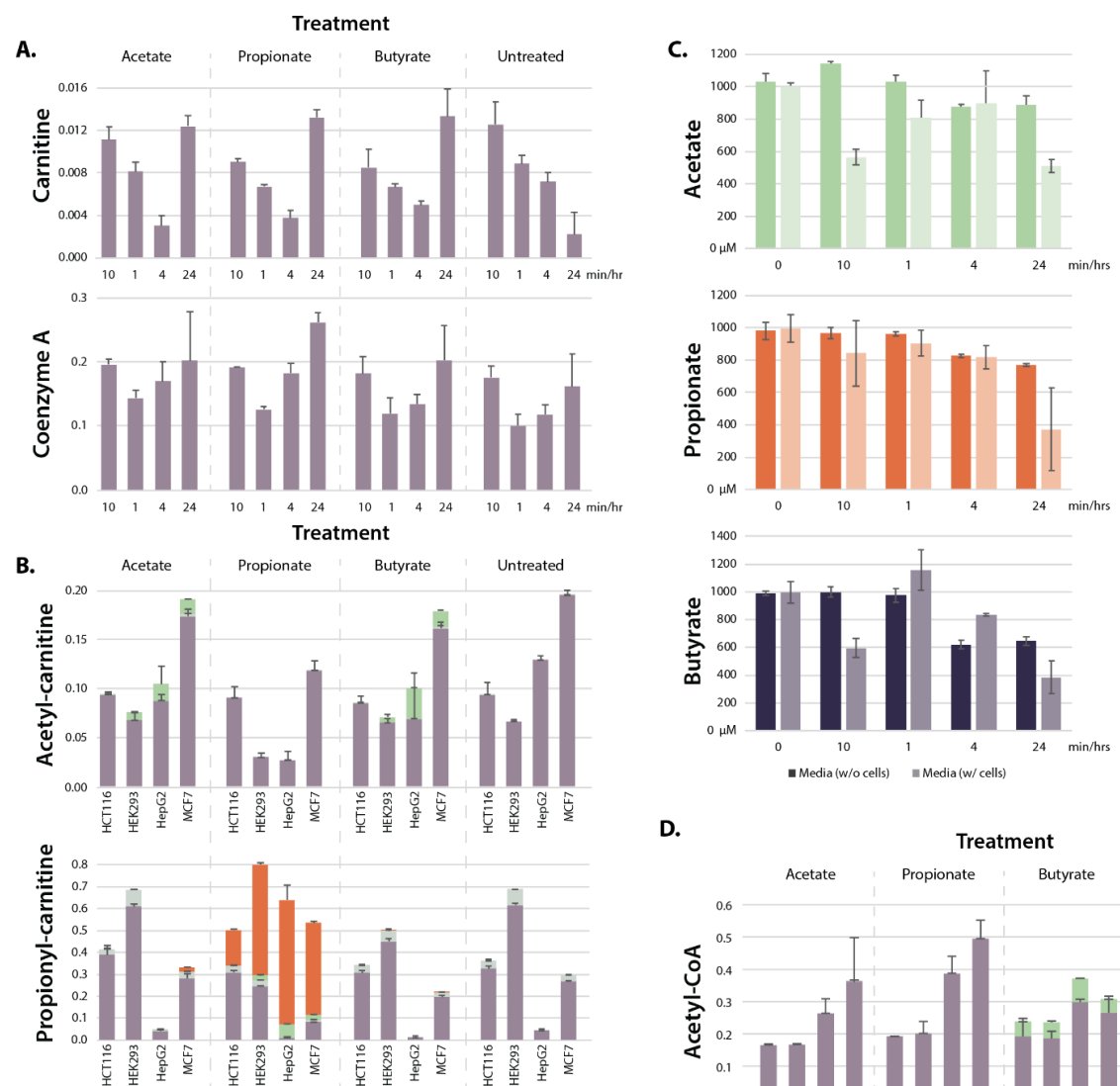

D.
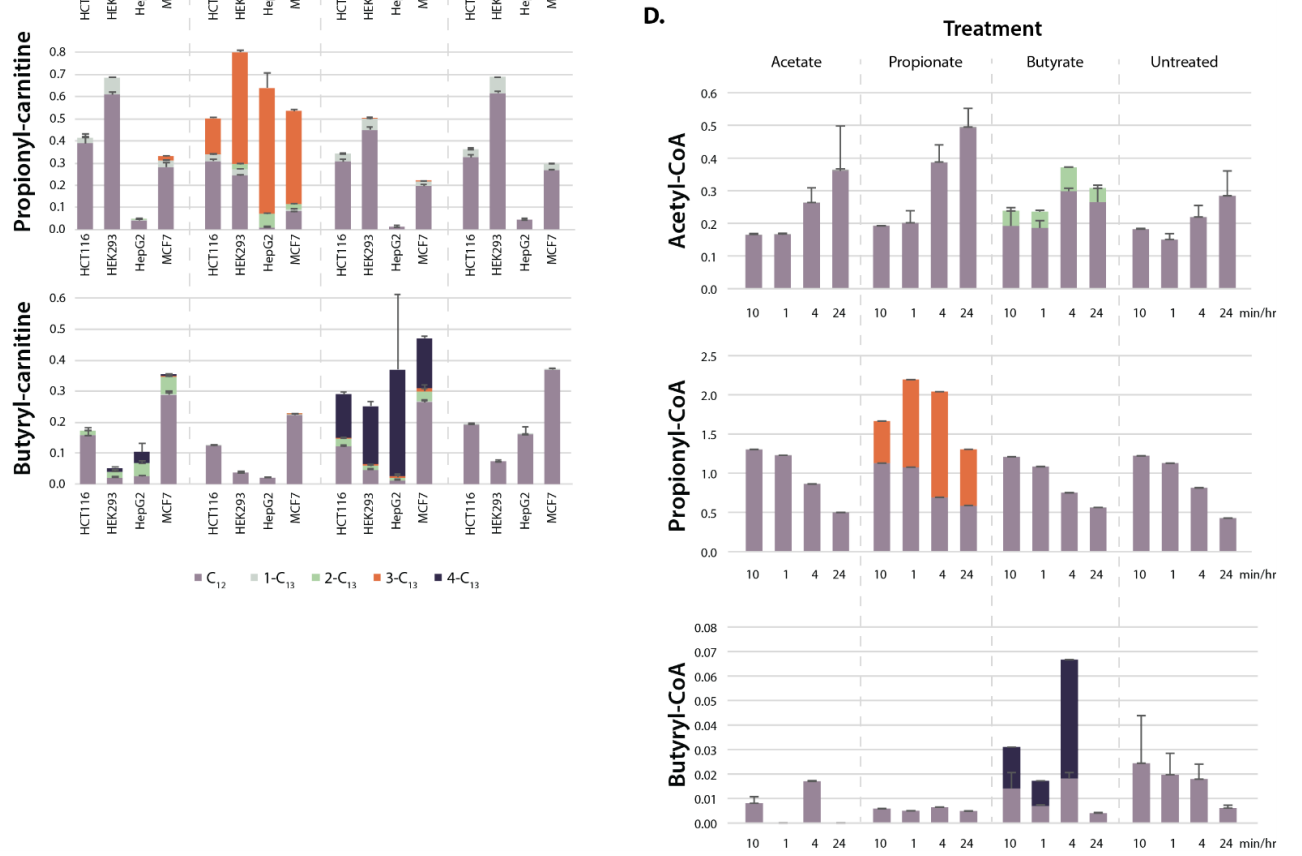

Supplemental Figure 2: A. Total carnitine and CoA levels in SCFA-treated cells over 24 hour time course B. Acyl-carnitine labeling in HCT116, HEK293, HepG2, and MCF7 cells after 1 hour treatment with $1 \mathrm{mM}$ SCFA. Values are normalized signal intensity C. SCFA concentrations in media incubated in dishes with or without cells over a 24 hour time course. D. Acetyl-CoA, propionyl-CoA, and butyryl-CoA labeling in HCT116 cells treated with $1 \mathrm{mM}$ SCFA over a 24 hour time course. All values are average and standard deviation of $\geq 3$ biological replicates. 
Supplemental Figure 3: Metabolism of SCFAs to acetyl-CoA is not necessary to induce hyperacetylation

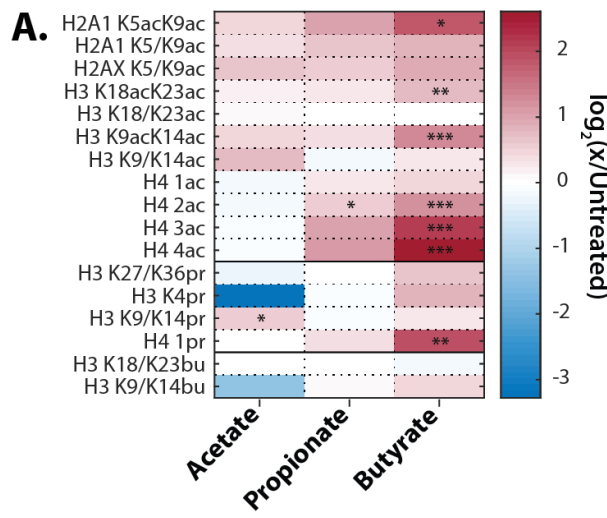

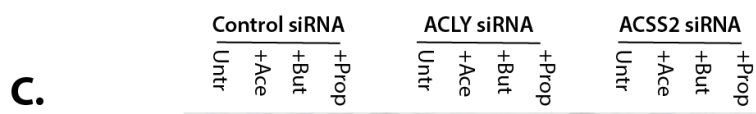
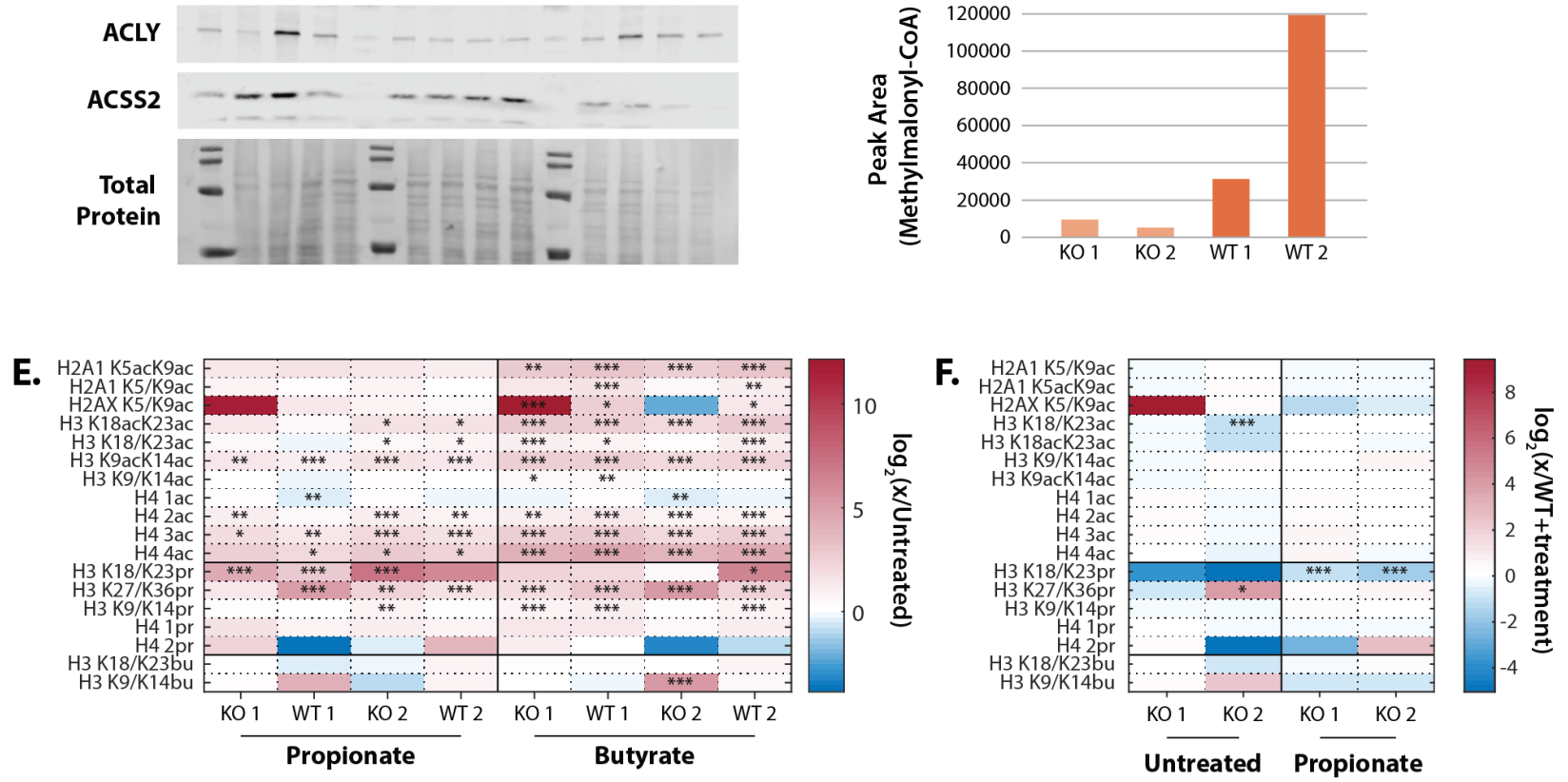

Supplemental Figure 3: A. Propionate and butyrate increase acetylation in HCT116 cells treated with non-targeting (NT) siRNA and 1 mM SCFA B. ACLY, ACSS2, and PCC siRNAs compared to NT siRNA + same SCFA treatment C. Knockdown efficiency of ACLY and ACSS2 siRNAs in cells treated with SCFAs. Full blots can be found in the Source Data file D. Methylmalonyl-CoA production in primary lymphoblasts from patients with propionic acidemia (KO 1/2) and family-matched controls (WT 1/2). Propionic acidemia is a rare genetic disease caused by mutations in PCC. Methylmalonyl-CoA is the product of PCC and was measured via HPLC E. Propionate and butyrate induce hyperacetylation in primary lymphoblasts from KO1/2 and WT1/2 cells F. Knockout of PCC does not affect histone hyperacetylation. Values are compared to WT cells + same SCFA treatment. For all samples, ${ }^{*}=p \leq 0.05,{ }^{* *}=p \leq 0.01$, ${ }^{* * *}=p \leq 0.001 . n=3$ per condition. 
Supplemental Figure 4: Recombinant p300 is actively auto-acylated.
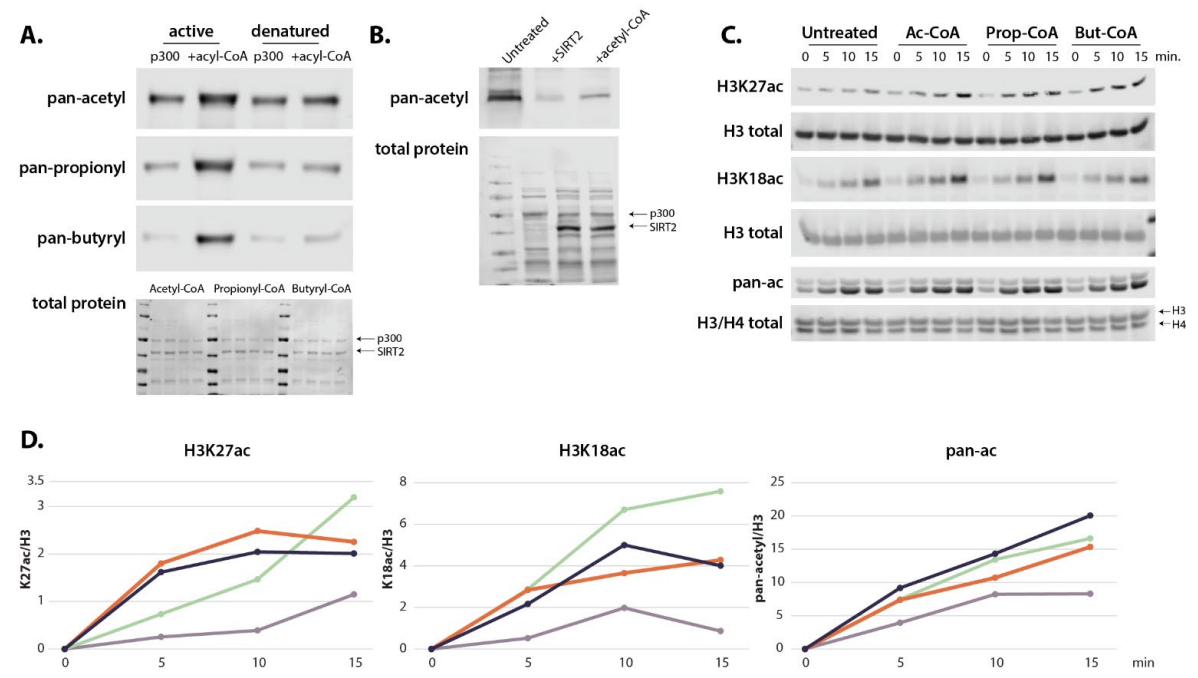

E.
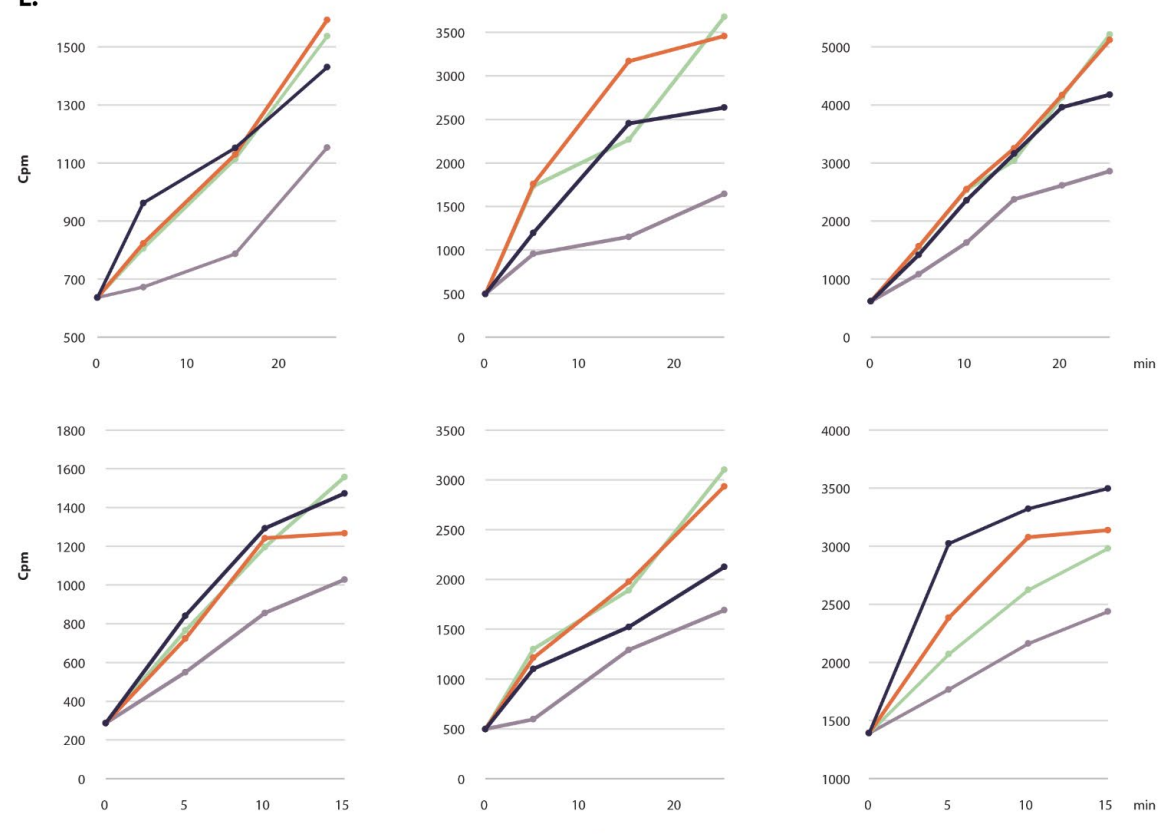

$\longrightarrow$ Unmodified $\simeq$ Acetylated $\longrightarrow$ Propionylated $\longrightarrow$ Butyrylated

Supplemental Figure 4: A. Acylation of active or denatured p300 B. SIRT2 treatment removes endogenous acetylation on recombinant p300 without inhibiting auto-acetylation after add-back of acetyl-CoA. C. Rate of histone acetylation after incubation with untreated, acetylated, propionylated, or butyrylated p300 using westerns blots and H3/H4 dimers. D. Graphical representation of histone blots. All gels are representative of at least three independent experiments performed on separate days. E. Radioactivity assays showing rate of acetylation by acetylated, propionylated, or butyrylated p300. Each replicate was performed with a different acylated enzyme preparation on a different day. Values and image quantification for all replicates available in the Supplementary Data file, full blots can be found in the Source Data file. 
Supplemental Figure 5: Representative western blots corresponding to Figure 4.

A.

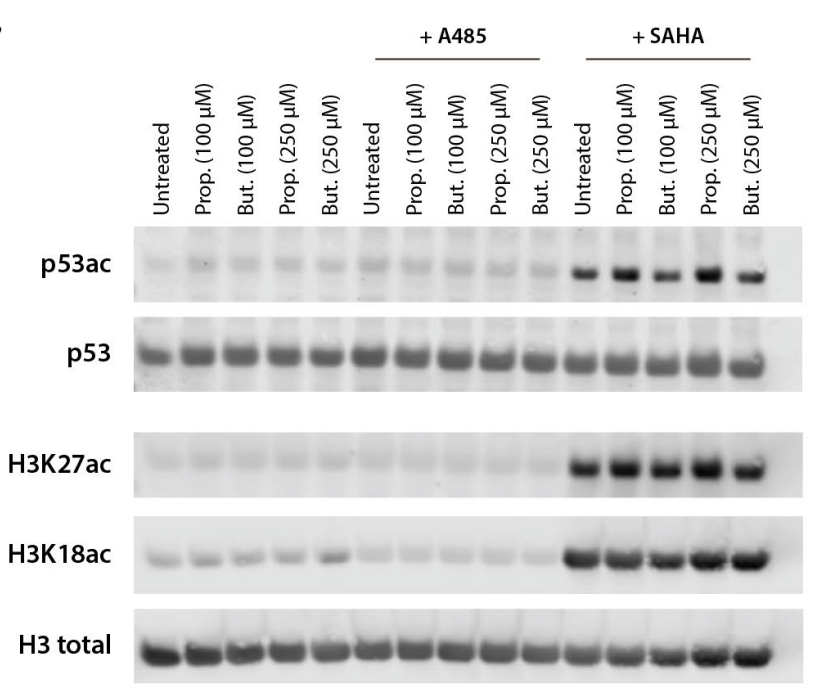

B.

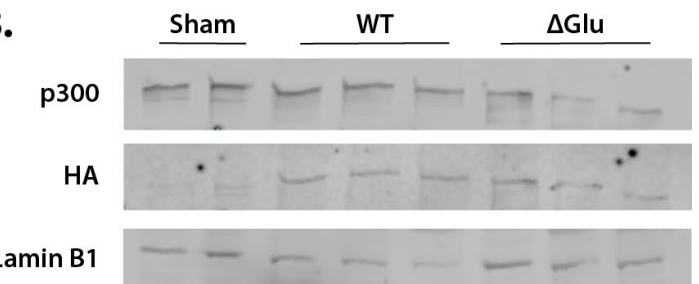

C.

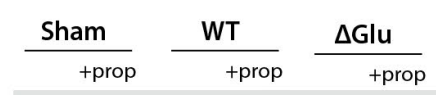

H3K27ac

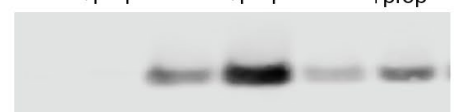

H3K18ac

H3

D.

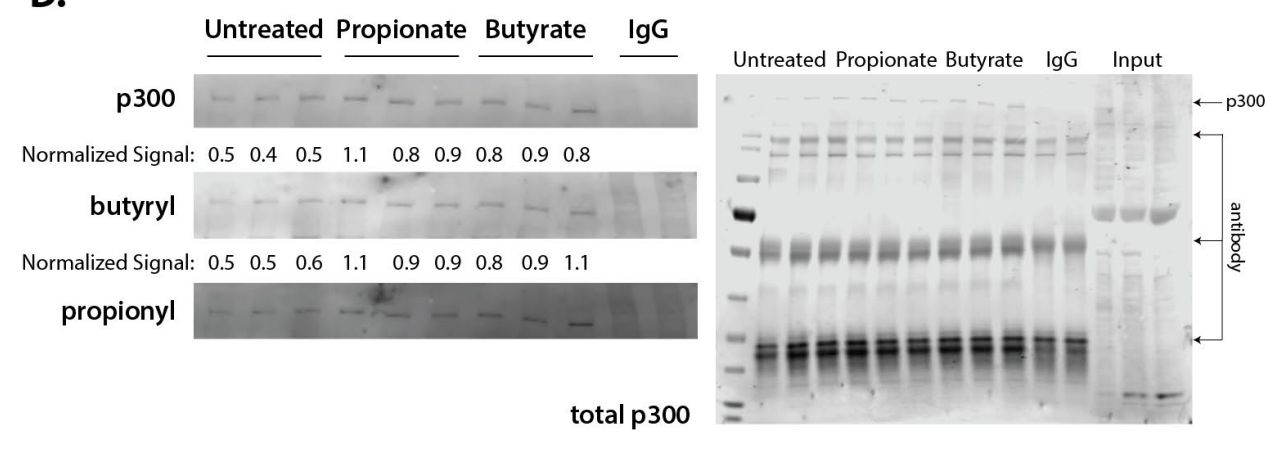

Supplemental Figure 5: A. Acetylation of H3K27ac, H3K18ac, and p53K382ac after treatment with A485, SAHA, and 100-250 $\mu \mathrm{M}$ of propionate/butyrate for 24 hours. B. Expression of HAtagged plasmids and p300 levels in cells transfected with sham, WT p300, or $\Delta$ Glu p300. C. Levels of H3K27ac, H3K18ac, and H3 in sham, WT p300, or $\Delta$ Glu p300-transfected cells. D. Levels of p300, butyrylation, and propionylation in p300 immunoprecipitated from HCT116 cells treated with $500 \mu \mathrm{M}$ propionate or butyrate for 1 hour. All experiments were performed at least 2 separate times with $n=3$ biological replicates. Values and image quantification for all replicates available in the Supplementary Data file, full blots can be found in the Source Data file. 


\section{References}

Abdelli, L. S., Samsam, A., \& Naser, S. A. (2019). Propionic Acid Induces Gliosis and Neuroinflammation through Modulation of PTEN/AKT Pathway in Autism Spectrum Disorder. Scientific Reports, 9(1), 1-12. https://doi.org/10.1038/s41598-019-45348-z

Albaugh, B. N., Arnold, K. M., \& Denu, J. M. (2011). KAT(ching) metabolism by the tail: Insight into the links between lysine acetyltransferases and metabolism. Chembiochem : $A$ European Journal of Chemical Biology, 12(2), 290-298. https://doi.org/10.1002/cbic.201000438

Al-Lahham, S. H., Peppelenbosch, M. P., Roelofsen, H., Vonk, R. J., \& Venema, K. (2010). Biological effects of propionic acid in humans; metabolism, potential applications and underlying mechanisms. Biochimica et Biophysica Acta (BBA) - Molecular and Cell Biology of Lipids, 1801(11), 1175-1183. https://doi.org/10.1016/J.BBALIP.2010.07.007

Bannister, A. J., \& Kouzarides, T. (2011). Regulation of chromatin by histone modifications. Cell Research, 21(3), 381-395. https://doi.org/10.1038/cr.2011.22

Basu, S. S., Mesaros, C., Gelhaus, S. L., \& Blair, I. A. (2011). Stable Isotope Labeling by Essential Nutrients in Cell Culture for Preparation of Labeled Coenzyme A and Its Thioesters. Analytical Chemistry, 83(4), 1363-1369. https://doi.org/10.1021/ac1027353

Bergman, E. N. (1990). Energy contributions of volatile fatty acids from the gastrointestinal tract in various species. Physiological Reviews, 70(2), 567-590. https://doi.org/10.1152/physrev.1990.70.2.567

Berndsen, C. E., \& Denu, J. M. (2008). Catalysis and Substrate Selection by Histone/Protein Lysine Acetyltransferases. Current Opinion in Structural Biology, 18(6), 682-689. https://doi.org/10.1016/j.sbi.2008.11.004

Biermann, J., Boyle, J., Pielen, A., \& Lagrèze, W. A. (2011). Histone deacetylase inhibitors sodium butyrate and valproic acid delay spontaneous cell death in purified rat retinal ganglion cells. Molecular Vision, 17, 395-403. 
Bird, A. R., Hayakawa, T., Marsono, Y., Gooden, J. M., Record, I. R., Correll, R. L., \& Topping, D. L. (2000). Coarse brown rice increases fecal and large bowel short-chain fatty acids and starch but lowers calcium in the large bowel of pigs. The Journal of Nutrition, 130(7), 1780-1787. https://doi.org/10.1093/jn/130.7.1780

Bloemen, J. G., Venema, K., van de Poll, M. C., Olde Damink, S. W., Buurman, W. A., \& Dejong, C. H. (2009). Short chain fatty acids exchange across the gut and liver in humans measured at surgery. Clinical Nutrition (Edinburgh, Scotland), 28(6), 657-661. https://doi.org/10.1016/j.clnu.2009.05.011

Boets, E., Gomand, S. V., Deroover, L., Preston, T., Vermeulen, K., Preter, V. D., Hamer, H. M., Mooter, G. V. den, Vuyst, L. D., Courtin, C. M., Annaert, P., Delcour, J. A., \& Verbeke, K. A. (2017). Systemic availability and metabolism of colonic-derived short-chain fatty acids in healthy subjects: A stable isotope study. The Journal of Physiology, 595(2), 541-555. https://doi.org/10.1113/JP272613

Bolduc, J.-F., Hany, L., Barat, C., Ouellet, M., \& Tremblay, M. J. (2017). Epigenetic Metabolite Acetate Inhibits Class I/II Histone Deacetylases, Promotes Histone Acetylation, and Increases HIV-1 Integration in CD4+ T Cells. Journal of Virology, 91(16). https://doi.org/10.1128/JVI.01943-16

Bose, S., Ramesh, V., \& Locasale, J. W. (2019). Acetate Metabolism in Physiology, Cancer, and Beyond. Trends in Cell Biology, 29(9), 695-703. https://doi.org/10.1016/j.tcb.2019.05.005

Brown, A. J., Goldsworthy, S. M., Barnes, A. A., Eilert, M. M., Tcheang, L., Daniels, D., Muir, A. I., Wigglesworth, M. J., Kinghorn, I., Fraser, N. J., Pike, N. B., Strum, J. C., Steplewski, K. M., Murdock, P. R., Holder, J. C., Marshall, F. H., Szekeres, P. G., Wilson, S., Ignar, D. M., ... Dowell, S. J. (2003). The Orphan G Protein-coupled Receptors GPR41 and GPR43 Are Activated by Propionate and Other Short Chain Carboxylic Acids. Journal of Biological Chemistry, 278(13), 11312-11319. https://doi.org/10.1074/jbc.M211609200 
Bulusu, V., Tumanov, S., Michalopoulou, E., van den Broek, N. J., MacKay, G., Nixon, C., Dhayade, S., Schug, Z. T., Vande Voorde, J., Blyth, K., Gottlieb, E., Vazquez, A., \& Kamphorst, J. J. (2017). Acetate Recapturing by Nuclear Acetyl-CoA Synthetase 2 Prevents Loss of Histone Acetylation during Oxygen and Serum Limitation. Cell Reports, 18(3), 647-658. https://doi.org/10.1016/j.celrep.2016.12.055

Candido, E. P. M., Reeves, R., \& Davie, J. R. (1978). Sodium butyrate inhibits histone deacetylation in cultured cells. Cell, 14(1), 105-113. https://doi.org/10.1016/00928674(78)90305-7

Caslini, C., Hong, S., Ban, Y. J., Chen, X. S., \& Ince, T. A. (2019). HDAC7 regulates histone 3 lysine 27 acetylation and transcriptional activity at super-enhancer-associated genes in breast cancer stem cells. Oncogene, 38(39), 6599-6614. https://doi.org/10.1038/s41388-019-0897-0

Chan, H. M., \& Thangue, N. B. L. (2001). p300/CBP proteins: HATs for transcriptional bridges and scaffolds. Journal of Cell Science, 114(13), 2363-2373.

Chang, P. V., Hao, L., Offermanns, S., \& Medzhitov, R. (2014). The microbial metabolite butyrate regulates intestinal macrophage function via histone deacetylase inhibition. Proceedings of the National Academy of Sciences of the United States of America, 111(6), 2247-2252. https://doi.org/10.1073/pnas.1322269111

Chen, Y., Sprung, R., Tang, Y., Ball, H., Sangras, B., Kim, S. C., Falck, J. R., Peng, J., Gu, W., \& Zhao, Y. (2007a). Lysine Propionylation and Butyrylation Are Novel Post-translational Modifications in Histones. Molecular \& Cellular Proteomics, 6(5), 812-819. https://doi.org/10.1074/mcp.M700021-MCP200

Chen, Y., Sprung, R., Tang, Y., Ball, H., Sangras, B., Kim, S. C., Falck, J. R., Peng, J., Gu, W., \& Zhao, Y. (2007b). Lysine propionylation and butyrylation are novel post-translational modifications in histones. Molecular \& Cellular Proteomics, 6(5), 812-819. https://doi.org/10.1074/mcp.M700021-MCP200 
Cheng, H.-H., Wang, K.-H., Chu, L., Chang, T.-C., Kuo, C.-C., \& Wu, K. K. (2014). Quiescent and Proliferative Fibroblasts Exhibit Differential p300 HAT Activation through Control of 5-Methoxytryptophan Production. PLOS ONE, 9(2), e88507. https://doi.org/10.1371/journal.pone.0088507

Cheng, Z., Tang, Y., Chen, Y., Kim, S., Liu, H., Li, S. S. C., Gu, W., \& Zhao, Y. (2009). Molecular Characterization of Propionyllysines in Non-histone Proteins. Molecular \& Cellular Proteomics : MCP, 8(1), 45-52. https://doi.org/10.1074/mcp.M800224-MCP200

Chriett, S., Dąbek, A., Wojtala, M., Vidal, H., Balcerczyk, A., \& Pirola, L. (2019). Prominent action of butyrate over $\beta$-hydroxybutyrate as histone deacetylase inhibitor, transcriptional modulator and anti-inflammatory molecule. Scientific Reports, 9(1), 1-14. https://doi.org/10.1038/s41598-018-36941-9

Clausen, M. R., \& Mortensen, P. B. (1994). Kinetic studies on the metabolism of short-chain fatty acids and glucose by isolated rat colonocytes. Gastroenterology, 106(2), 423-432. https://doi.org/10.5555/uri:pii:0016508594906017

Clausen, M. R., \& Mortensen, P. B. (1995). Kinetic studies on colonocyte metabolism of short chain fatty acids and glucose in ulcerative colitis. Gut, 37(5), 684-689.

Corfe, B. M. (2012). Hypothesis: Butyrate is not an HDAC inhibitor, but a product inhibitor of deacetylation. Molecular BioSystems, 8(6), 1609-1612. https://doi.org/10.1039/C2MB25028D

Cuisset, L., Tichonicky, L., \& Delpech, M. (1998). A Protein Phosphatase Is Involved in the Inhibition of Histone Deacetylation by Sodium Butyrate. Biochemical and Biophysical Research Communications, 246(3), 760-764. https://doi.org/10.1006/bbrc.1998.8698 Cuisset, L., Tichonicky, L., Jaffray, P., \& Delpech, M. (1997). The effects of sodium butyrate on transcription are mediated through activation of a protein phosphatase. The Journal of Biological Chemistry, 272(39), 24148-24153. https://doi.org/10.1074/jbc.272.39.24148 
Cummings, J. H., Pomare, E. W., Branch, W. J., Naylor, C. P., \& Macfarlane, G. T. (1987).

Short chain fatty acids in human large intestine, portal, hepatic and venous blood. Gut, 28(10), 1221-1227.

Dai, L., Peng, C., Montellier, E., Lu, Z., Chen, Y., Ishii, H., Debernardi, A., Buchou, T., Rousseaux, S., Jin, F., Sabari, B. R., Deng, Z., Allis, C. D., Ren, B., Khochbin, S., \& Zhao, Y. (2014). Lysine 2-hydroxyisobutyrylation is a widely distributed active histone mark. Nature Chemical Biology, 10(5), 365-370. https://doi.org/10.1038/nchembio.1497

Dancy, B. M., \& Cole, P. A. (2015). Protein Lysine Acetylation by p300/CBP. Chemical Reviews, 115(6), 2419-2452. https://doi.org/10.1021/cr500452k

Davie, J. R. (2003). Inhibition of histone deacetylase activity by butyrate. The Journal of Nutrition, 133(7 Suppl), 2485S-2493S.

den Besten, G., van Eunen, K., Groen, A. K., Venema, K., Reijngoud, D.-J., \& Bakker, B. M. (2013). The role of short-chain fatty acids in the interplay between diet, gut microbiota, and host energy metabolism. Journal of Lipid Research, 54(9), 2325-2340. https://doi.org/10.1194/jlr.R036012

Donohoe, D. R., Collins, L. B., Wali, A., Bigler, R., Sun, W., \& Bultman, S. J. (2012). The Warburg effect dictates the mechanism of butyrate-mediated histone acetylation and cell proliferation. Molecular Cell, 48(4), 612-626.

https://doi.org/10.1016/j.molcel.2012.08.033

Donohoe, D. R., Holley, D., Collins, L. B., Montgomery, S. A., Whitmore, A. C., Hillhouse, A., Curry, K. P., Renner, S. W., Greenwalt, A., Ryan, E. P., Godfrey, V., Heise, M. T., Threadgill, D. S., Han, A., Swenberg, J. A., Threadgill, D. W., \& Bultman, S. J. (2014). A gnotobiotic mouse model demonstrates that dietary fiber protects against colorectal tumorigenesis in a microbiota- and butyrate-dependent manner. Cancer Discovery, 4(12), 1387-1397. https://doi.org/10.1158/2159-8290.CD-14-0501 
Fan, J., Krautkramer, K. A., Feldman, J. L., \& Denu, J. M. (2015). Metabolic Regulation of Histone Post-Translational Modifications. ACS Chemical Biology, 10(1), 95-108. https://doi.org/10.1021/cb500846u

Gao, X., Lin, S.-H., Ren, F., Li, J.-T., Chen, J.-J., Yao, C.-B., Yang, H.-B., Jiang, S.-X., Yan, G.Q., Wang, D., Wang, Y., Liu, Y., Cai, Z., Xu, Y.-Y., Chen, J., Yu, W., Yang, P.-Y., \& Lei, Q.-Y. (2016). Acetate functions as an epigenetic metabolite to promote lipid synthesis under hypoxia. Nature Communications, 7(1), 1-14. https://doi.org/10.1038/ncomms11960

Gao, Z., Yin, J., Zhang, J., Ward, R. E., Martin, R. J., Lefevre, M., Cefalu, W. T., \& Ye, J. (2009). Butyrate Improves Insulin Sensitivity and Increases Energy Expenditure in Mice. Diabetes, 58(7), 1509-1517. https://doi.org/10.2337/db08-1637

Gibson, P. (2000). The intracellular target of butyrate's actions: HDAC or HDON'T? Gut, 46(4), 447-448. https://doi.org/10.1136/gut.46.4.447

Goodman, R. H., \& Smolik, S. (2000). CBP/p300 in cell growth, transformation, and development. Genes \& Development, 14(13), 1553-1577. https://doi.org/10.1101/gad.14.13.1553

Goudarzi, A., Zhang, D., Huang, H., Barral, S., Kwon, O. K., Qi, S., Tang, Z., Buchou, T., Vitte, A.-L., He, T., Cheng, Z., Montellier, E., Gaucher, J., Curtet, S., Debernardi, A., Charbonnier, G., Puthier, D., Petosa, C., Panne, D., ... Khochbin, S. (2016). Dynamic Competing Histone H4 K5K8 Acetylation and Butyrylation Are Hallmarks of Highly Active Gene Promoters. Molecular Cell, 62(2), 169-180.

https://doi.org/10.1016/j.molcel.2016.03.014

Granja, A. G., Perkins, N. D., \& Revilla, Y. (2008). A238L inhibits NF-ATc2, NF-kappa B, and cJun activation through a novel mechanism involving protein kinase C-theta-mediated upregulation of the amino-terminal transactivation domain of p300. Journal of Immunology (Baltimore, Md.: 1950), 180(4), 2429-2442. https://doi.org/10.4049/jimmunol.180.4.2429 
Hague, A., Manning, A. M., Hanlon, K. A., Hart, D., Paraskeva, C., \& Huschtscha, L. I. (1993). Sodium butyrate induces apoptosis in human colonic tumour cell lines in a p53independent pathway: Implications for the possible role of dietary fibre in the prevention of large-bowel cancer. International Journal of Cancer, 55(3), 498-505. https://doi.org/10.1002/ijc.2910550329

Hamer, H. M., Jonkers, D., Venema, K., Vanhoutvin, S., Troost, F. J., \& Brummer, R.-J. (2008). Review article: The role of butyrate on colonic function. Alimentary Pharmacology \& Therapeutics, 27(2), 104-119. https://doi.org/10.1111/j.1365-2036.2007.03562.x

Henry, R. A., Kuo, Y.-M., \& Andrews, A. J. (2013). Differences in Specificity and Selectivity Between CBP and p300 Acetylation of Histone H3 and H3/H4. Biochemistry, 52(34), 5746-5759. https://doi.org/10.1021/bi400684q

Hinnebusch, B. F., Meng, S., Wu, J. T., Archer, S. Y., \& Hodin, R. A. (2002). The Effects of Short-Chain Fatty Acids on Human Colon Cancer Cell Phenotype Are Associated with Histone Hyperacetylation. The Journal of Nutrition, 132(5), 1012-1017. https://doi.org/10.1093/jn/132.5.1012

Hsu, C.-W., Shou, D., Huang, R., Khuc, T., Dai, S., Zheng, W., Klumpp-Thomas, C., \& Xia, M. (2016). Identification of HDAC Inhibitors Using a Cell-Based HDAC I/II Assay. Journal of Biomolecular Screening, 21(6), 643-652. https://doi.org/10.1177/1087057116629381

Huber, K., Doyon, G., Plaks, J., Fyne, E., Mellors, J. W., \& Sluis-Cremer, N. (2011). Inhibitors of histone deacetylases: Correlation between isoform specificity and reactivation of HIV type 1 (HIV-1) from latently infected cells. The Journal of Biological Chemistry, 286(25), 22211-22218. https://doi.org/10.1074/jbc.M110.180224

Inoue, D., Tsujimoto, G., \& Kimura, I. (2014). Regulation of Energy Homeostasis by GPR41. Frontiers in Endocrinology, 5, 81. https://doi.org/10.3389/fendo.2014.00081

Jain, S., Wei, J., Mitrani, L. R., \& Bishopric, N. H. (2012). Auto-acetylation stabilizes p300 in cardiac myocytes during acute oxidative stress, promoting STAT3 accumulation and cell 
survival. Breast Cancer Research and Treatment, 135(1), 103-114.

https://doi.org/10.1007/s10549-012-2069-6

Jenkins, D. J., Vuksan, V., Kendall, C. W., Würsch, P., Jeffcoat, R., Waring, S., Mehling, C. C., Vidgen, E., Augustin, L. S., \& Wong, E. (1998). Physiological effects of resistant starches on fecal bulk, short chain fatty acids, blood lipids and glycemic index. Journal of the American College of Nutrition, 17(6), 609-616.

https://doi.org/10.1080/07315724.1998.10718810

Kaczmarska, Z., Ortega, E., Goudarzi, A., Huang, H., Kim, S., Márquez, J. A., Zhao, Y., Khochbin, S., \& Panne, D. (2017). Structure of p300 in complex with acyl-CoA variants. Nature Chemical Biology, 13(1), 21-29. https://doi.org/10.1038/nchembio.2217

Karanam, B., Jiang, L., Wang, L., Kelleher, N. L., \& Cole, P. A. (2006). Kinetic and Mass Spectrometric Analysis of p300 Histone Acetyltransferase Domain Autoacetylation. Journal of Biological Chemistry, 281(52), 40292-40301.

https://doi.org/10.1074/jbc.M608813200

Karch, K. R., DeNizio, J. E., Black, B. E., \& Garcia, B. A. (2013). Identification and interrogation of combinatorial histone modifications. Frontiers in Genetics, 4, 264. https://doi.org/10.3389/fgene.2013.00264

Kebede, A. F., Nieborak, A., Shahidian, L. Z., Le Gras, S., Richter, F., Gómez, D. A., Baltissen, M. P., Meszaros, G., Magliarelli, H. de F., Taudt, A., Margueron, R., Colomé-Tatché, M., Ricci, R., Daujat, S., Vermeulen, M., Mittler, G., \& Schneider, R. (2017). Histone propionylation is a mark of active chromatin. Nature Structural \& Molecular Biology. https://doi.org/10.1038/nsmb.3490

Kelly, R. D. W., Chandru, A., Watson, P. J., Song, Y., Blades, M., Robertson, N. S., Jamieson, A. G., Schwabe, J. W. R., \& Cowley, S. M. (2018). Histone deacetylase (HDAC) 1 and 2 complexes regulate both histone acetylation and crotonylation in vivo. Scientific Reports, 8(1), 14690. https://doi.org/10.1038/s41598-018-32927-9 
Kespohl, M., Vachharajani, N., Luu, M., Harb, H., Pautz, S., Wolff, S., Sillner, N., Walker, A., Schmitt-Kopplin, P., Boettger, T., Renz, H., Offermanns, S., Steinhoff, U., \& Visekruna, A. (2017). The Microbial Metabolite Butyrate Induces Expression of Th1-Associated Factors in CD4+ T Cells. Frontiers in Immunology, 8. https://doi.org/10.3389/fimmu.2017.01036

Kiefer, J., Beyer-Sehlmeyer, G., \& Pool-Zobel, B. L. (2006). Mixtures of SCFA, composed according to physiologically available concentrations in the gut lumen, modulate histone acetylation in human HT29 colon cancer cells. British Journal of Nutrition, 96(5), 803810. https://doi.org/10.1017/BJN20061948

Koh, A., De Vadder, F., Kovatcheva-Datchary, P., \& Backhed, F. (2016). From Dietary Fiber to Host Physiology: Short-Chain Fatty Acids as Key Bacterial Metabolites. Cell, 165(6), 1332-1345. https://doi.org/10.1016/j.cell.2016.05.041

Kouzarides, T. (2007). Chromatin Modifications and Their Function. Cell, 128(4), 693-705. https://doi.org/10.1016/j.cell.2007.02.005

Krautkramer, K. A., Kreznar, J. H., Romano, K. A., Vivas, E. I., Barrett-Wilt, G. A., Rabaglia, M. E., Keller, M. P., Attie, A. D., Rey, F. E., \& Denu, J. M. (2016). Diet-Microbiota Interactions Mediate Global Epigenetic Programming in Multiple Host Tissues. Molecular Cell, 64(5), 982-992. https://doi.org/10.1016/j.molcel.2016.10.025

Krautkramer, K. A., Reiter, L., Denu, J. M., \& Dowell, J. A. (2015). Quantification of SAHADependent Changes in Histone Modifications Using Data-Independent Acquisition Mass Spectrometry. Journal of Proteome Research, 14(8), 3252-3262. https://doi.org/10.1021/acs.jproteome.5b00245

Kumar, H., Lund, R., Laiho, A., Lundelin, K., Ley, R. E., Isolauri, E., \& Salminen, S. (2014). Gut microbiota as an epigenetic regulator: Pilot study based on whole-genome methylation analysis. MBio, 5(6), e02113-14. https://doi.org/10.1128/mBio.02113-14 
Lasko, L. M., Jakob, C. G., Edalji, R. P., Qiu, W., Montgomery, D., Digiammarino, E. L., Hansen, T. M., Risi, R. M., Frey, R., Manaves, V., Shaw, B., Algire, M., Hessler, P., Lam, L. T., Uziel, T., Faivre, E., Ferguson, D., Buchanan, F. G., Martin, R. L., ... Bromberg, K. D. (2017). Discovery of a potent catalytic p300/CBP inhibitor that targets lineage-specific tumors. Nature, 550(7674), 128-132. https://doi.org/10.1038/nature24028

Leemhuis, H., Packman, L. C., Nightingale, K. P., \& Hollfelder, F. (2008). The Human Histone Acetyltransferase P/CAF is a Promiscuous Histone Propionyltransferase.

ChemBioChem, 9(4), 499-503. https://doi.org/10.1002/cbic.200700556

Levrat, M. A., Rémésy, C., \& Demigné, C. (1991). High propionic acid fermentations and mineral accumulation in the cecum of rats adapted to different levels of inulin. The Journal of Nutrition, 121(11), 1730-1737. https://doi.org/10.1093/jn/121.11.1730

Li, Q., Han, Y., Dy, A. B. C., \& Hagerman, R. J. (2017). The Gut Microbiota and Autism Spectrum Disorders. Frontiers in Cellular Neuroscience, 11, 120. https://doi.org/10.3389/fncel.2017.00120

Lin, H. V., Frassetto, A., Kowalik, E. J., Nawrocki, A. R., Lu, M. M., Kosinski, J. R., Hubert, J. A., Szeto, D., Yao, X., Forrest, G., \& Marsh, D. J. (2012). Butyrate and propionate protect against diet-induced obesity and regulate gut hormones via free fatty acid receptor 3independent mechanisms. PloS One, 7(4), e35240. https://doi.org/10.1371/journal.pone.0035240

Liu, X., Cooper, D. E., Cluntun, A. A., Warmoes, M. O., Zhao, S., Reid, M. A., Liu, J., Lund, P. J., Lopes, M., Garcia, B. A., Wellen, K. E., Kirsch, D. G., \& Locasale, J. W. (2018). Acetate Production from Glucose and Coupling to Mitochondrial Metabolism in Mammals. Cell, 175(2), 502-513.e13. https://doi.org/10.1016/j.cell.2018.08.040 Liu, X., Wang, L., Zhao, K., Thompson, P. R., Hwang, Y., Marmorstein, R., \& Cole, P. A. (2008). The structural basis of protein acetylation by the p300/CBP transcriptional coactivator. Nature, 451(7180), 846-850. https://doi.org/10.1038/nature06546 
Liu, Y.-N., Liu, T.-T., Fan, Y.-L., Niu, D.-M., Chien, Y.-H., Chou, Y.-Y., Lee, N.-C., Hsiao, K.-J., \& Chiu, Y.-H. (2016). Measuring propionyl-CoA carboxylase activity in phytohemagglutinin stimulated lymphocytes using high performance liquid chromatography. Clinica Chimica Acta; International Journal of Clinical Chemistry, 453, 13-20.

https://doi.org/10.1016/j.cca.2015.11.023

Lu, Y., Yao, D., \& Chen, C. (2013). 2-Hydrazinoquinoline as a Derivatization Agent for LC-MSBased Metabolomic Investigation of Diabetic Ketoacidosis. Metabolites, 3(4), 993-1010. https://doi.org/10.3390/metabo3040993

Marks, P. A., \& Breslow, R. (2007). Dimethyl sulfoxide to vorinostat: Development of this histone deacetylase inhibitor as an anticancer drug. Nature Biotechnology, 25(1), 84-90. https://doi.org/10.1038/nbt1272

Marsono, Y., Illman, R. J., Clarke, J. M., Trimble, R. P., \& Topping, D. L. (1993). Plasma lipids and large bowel volatile fatty acids in pigs fed on white rice, brown rice and rice bran. The British Journal of Nutrition, 70(2), 503-513. https://doi.org/10.1079/bjn19930144

Milton, S. G., Mathew, O. P., Yatsu, F. M., \& Ranganna, K. (2012). Differential Cellular and Molecular Effects of Butyrate and Trichostatin A on Vascular Smooth Muscle Cells. Pharmaceuticals, 5(9), 925-943. https://doi.org/10.3390/ph5090925

Müller, M., Hernández, M. A. G., Goossens, G. H., Reijnders, D., Holst, J. J., Jocken, J. W. E., Eijk, H. van, Canfora, E. E., \& Blaak, E. E. (2019). Circulating but not faecal short-chain fatty acids are related to insulin sensitivity, lipolysis and GLP-1 concentrations in humans. Scientific Reports, 9(1), 1-9. https://doi.org/10.1038/s41598-019-48775-0

Muschet, C., Möller, G., Prehn, C., de Angelis, M. H., Adamski, J., \& Tokarz, J. (2016).

Removing the bottlenecks of cell culture metabolomics: Fast normalization procedure, correlation of metabolites to cell number, and impact of the cell harvesting method. Metabolomics, 12(10), 151. https://doi.org/10.1007/s11306-016-1104-8 
Ortega, E., Rengachari, S., Ibrahim, Z., Hoghoughi, N., Gaucher, J., Holehouse, A. S., Khochbin, S., \& Panne, D. (2018). Transcription factor dimerization activates the p300 acetyltransferase. Nature, 562(7728), 538-544. https://doi.org/10.1038/s41586-0180621-1

Parada Venegas, D., De la Fuente, M. K., Landskron, G., González, M. J., Quera, R., Dijkstra, G., Harmsen, H. J. M., Faber, K. N., \& Hermoso, M. A. (2019). Short Chain Fatty Acids (SCFAs)-Mediated Gut Epithelial and Immune Regulation and Its Relevance for Inflammatory Bowel Diseases. Frontiers in Immunology, 10. https://doi.org/10.3389/fimmu.2019.00277

Peng, L., Li, Z.-R., Green, R. S., Holzman, I. R., \& Lin, J. (2009). Butyrate enhances the intestinal barrier by facilitating tight junction assembly via activation of AMP-activated protein kinase in Caco-2 cell monolayers. The Journal of Nutrition, 139(9), 1619-1625. https://doi.org/10.3945/jn.109.104638

Prasad, K. N., \& Sinha, P. K. (1976). Effect of sodium butyrate on mammalian cells in culture: A review. In Vitro, 12(2), 125-132. https://doi.org/10.1007/bf02796360

Priyadarshini, M., Kotlo, K. U., Dudeja, P. K., \& Layden, B. T. (2018). Role of Short Chain Fatty Acid Receptors in Intestinal Physiology and Pathophysiology. Comprehensive Physiology, 8(3), 1091-1115. https://doi.org/10.1002/cphy.c170050

Rahman, Md. M., Kukita, A., Kukita, T., Shobuike, T., Nakamura, T., \& Kohashi, O. (2003). Two histone deacetylase inhibitors, trichostatin A and sodium butyrate, suppress differentiation into osteoclasts but not into macrophages. Blood, 101(9), 3451-3459. https://doi.org/10.1182/blood-2002-08-2622

Rajan, A., Shi, H., \& Xue, B. (2018). Class I and II Histone Deacetylase Inhibitors Differentially Regulate Thermogenic Gene Expression in Brown Adipocytes. Scientific Reports, 8(1), 13072. https://doi.org/10.1038/s41598-018-31560-w 
Rickard, K. L., Gibson, P. R., Young, G. P., \& Phillips, W. A. (1999). Activation of protein kinase C augments butyrate-induced differentiation and turnover in human colonic epithelial cells in vitro. Carcinogenesis, 20(6), 977-984. https://doi.org/10.1093/carcin/20.6.977

Ringel, A. E., \& Wolberger, C. (2016). Structural basis for acyl-group discrimination by human Gcn5L2. Acta Crystallographica. Section D, Structural Biology, 72(Pt 7), 841-848. https://doi.org/10.1107/S2059798316007907

Ríos-Covián, D., Ruas-Madiedo, P., Margolles, A., Gueimonde, M., de los Reyes-Gavilán, C. G., \& Salazar, N. (2016). Intestinal Short Chain Fatty Acids and their Link with Diet and Human Health. Frontiers in Microbiology, 7. https://doi.org/10.3389/fmicb.2016.00185

Roediger, W. E. (1982). Utilization of nutrients by isolated epithelial cells of the rat colon. Gastroenterology, 83(2), 424-429.

Romano, K. A., Martinez-del Campo, A., Kasahara, K., Chittim, C. L., Vivas, E. I., AmadorNoguez, D., Balskus, E. P., \& Rey, F. E. (2017). Metabolic, Epigenetic, and Transgenerational Effects of Gut Bacterial Choline Consumption. Cell Host \& Microbe, 22(3), 279-290.e7. https://doi.org/10.1016/j.chom.2017.07.021

Roth, S. Y., Denu, J. M., \& Allis, C. D. (2001). Histone Acetyltransferases. Annual Review of Biochemistry, 70(1), 81-120. https://doi.org/10.1146/annurev.biochem.70.1.81 Sassone-Corsi, P. (2013). When Metabolism and Epigenetics Converge. Science, 339(6116), 148-150. https://doi.org/10.1126/science.1233423

Sekhavat, A., Sun, J.-M., \& Davie, J. R. (2007). Competitive inhibition of histone deacetylase activity by trichostatin A and butyrate. Biochemistry and Cell Biology, 85(6), 751-758. https://doi.org/10.1139/o07-145

Sengupta, S., Muir, J. G., \& Gibson, P. R. (2006). Does butyrate protect from colorectal cancer? Journal of Gastroenterology and Hepatology, 21(1), 209-218. https://doi.org/10.1111/j.1440-1746.2006.04213.x 
Siavoshian, S., Segain, J.-P., Kornprobst, M., Bonnet, C., Cherbut, C., Galmiche, J.-P., \& Blottière, H. M. (2000). Butyrate and trichostatin A effects on the proliferation/differentiation of human intestinal epithelial cells: Induction of cyclin D3 and p21 expression. Gut, 46(4), 507-514. https://doi.org/10.1136/gut.46.4.507

Sidoli, S., Bhanu, N. V., Karch, K. R., Wang, X., \& Garcia, B. A. (2016). Complete Workflow for Analysis of Histone Post-translational Modifications Using Bottom-up Mass Spectrometry: From Histone Extraction to Data Analysis. Journal of Visualized Experiments, 111. https://doi.org/10.3791/54112

Silva, L. G., Ferguson, B. S., Avila, A. S., \& Faciola, A. P. (2018). Sodium propionate and sodium butyrate effects on histone deacetylase (HDAC) activity, histone acetylation, and inflammatory gene expression in bovine mammary epithelial cells. Journal of Animal Science, 96(12), 5244-5252. https://doi.org/10.1093/jas/sky373

Simithy, J., Sidoli, S., Yuan, Z.-F., Coradin, M., Bhanu, N. V., Marchione, D. M., Klein, B. J., Bazilevsky, G. A., McCullough, C. E., Magin, R. S., Kutateladze, T. G., Snyder, N. W., Marmorstein, R., \& Garcia, B. A. (2017). Characterization of histone acylations links chromatin modifications with metabolism. Nature Communications, 8(1), 1141. https://doi.org/10.1038/s41467-017-01384-9

Singh, N., Gurav, A., Sivaprakasam, S., Brady, E., Padia, R., Shi, H., Thangaraju, M., Prasad, P. D., Manicassamy, S., Munn, D. H., Lee, J. R., Offermanns, S., \& Ganapathy, V. (2014). Activation of Gpr109a, receptor for niacin and the commensal metabolite butyrate, suppresses colonic inflammation and carcinogenesis. Immunity, 40(1), 128139. https://doi.org/10.1016/j.immuni.2013.12.007

Takahashi, H., McCaffery, J. M., Irizarry, R. A., \& Boeke, J. D. (2006). Nucleocytosolic AcetylCoenzyme A Synthetase Is Required for Histone Acetylation and Global Transcription. Molecular Cell, 23(2), 207-217. https://doi.org/10.1016/j.molcel.2006.05.040 
Tan, J., McKenzie, C., Potamitis, M., Thorburn, A. N., Mackay, C. R., \& Macia, L. (2014).

Chapter Three-The Role of Short-Chain Fatty Acids in Health and Disease. In F. W. Alt (Ed.), Advances in Immunology (Vol. 121, pp. 91-119). Academic Press.

https://doi.org/10.1016/B978-0-12-800100-4.00003-9

Thangaraju, M., Cresci, G. A., Liu, K., Ananth, S., Gnanaprakasam, J. P., Browning, D. D.,

Mellinger, J. D., Smith, S. B., Digby, G. J., Lambert, N. A., Prasad, P. D., \& Ganapathy, V. (2009). GPR109A Is a G-protein-Coupled Receptor for the Bacterial Fermentation

Product Butyrate and Functions as a Tumor Suppressor in Colon. Cancer Research. https://doi.org/10.1158/0008-5472.CAN-08-4466

Thomas, S. P., Haws, S. A., Borth, L. E., \& Denu, J. M. (2019). A practical guide for analysis of histone post-translational modifications by mass spectrometry: Best practices and pitfalls. Methods. https://doi.org/10.1016/j.ymeth.2019.12.001

Thompson, P. R., Wang, D., Wang, L., Fulco, M., Pediconi, N., Zhang, D., An, W., Ge, Q., Roeder, R. G., Wong, J., Levrero, M., Sartorelli, V., Cotter, R. J., \& Cole, P. A. (2004). Regulation of the p300 HAT domain via a novel activation loop. Nature Structural \& Molecular Biology, 11(4), 308-315. https://doi.org/10.1038/nsmb740

Trefely, S., Lovell, C. D., Snyder, N. W., \& Wellen, K. E. (2020). Compartmentalised acyl-CoA metabolism and roles in chromatin regulation. Molecular Metabolism, 38, 100941. https://doi.org/10.1016/j.molmet.2020.01.005

Usami, M., Kishimoto, K., Ohata, A., Miyoshi, M., Aoyama, M., Fueda, Y., \& Kotani, J. (2008). Butyrate and trichostatin $\mathrm{A}$ attenuate nuclear factor $\mathrm{kB}$ activation and tumor necrosis factor $\alpha$ secretion and increase prostaglandin E2 secretion in human peripheral blood mononuclear cells. Nutrition Research, 28(5), 321-328.

https://doi.org/10.1016/J.NUTRES.2008.02.012 
Velázquez, M., Davies, C., Marett, R., Slavin, J. L., \& Feirtag, J. M. (2000). Effect of

Oligosaccharides and Fibre Substitutes on Short-chain Fatty Acid Production by Human

Faecal Microflora. Anaerobe, 6(2), 87-92. https://doi.org/10.1006/anae.1999.0318

Vinolo, M. A. R., Rodrigues, H. G., Hatanaka, E., Sato, F. T., Sampaio, S. C., \& Curi, R. (2011). Suppressive effect of short-chain fatty acids on production of proinflammatory mediators by neutrophils. The Journal of Nutritional Biochemistry, 22(9), 849-855.

https://doi.org/10.1016/j.jnutbio.2010.07.009

Vogelauer, M., Krall, A. S., McBrian, M. A., Li, J.-Y., \& Kurdistani, S. K. (2012). Stimulation of Histone Deacetylase Activity by Metabolites of Intermediary Metabolism. Journal of Biological Chemistry, 287(38), 32006-32016. https://doi.org/10.1074/jbc.M112.362467

Waldecker, M., Kautenburger, T., Daumann, H., Busch, C., \& Schrenk, D. (2008). Inhibition of histone-deacetylase activity by short-chain fatty acids and some polyphenol metabolites formed in the colon. The Journal of Nutritional Biochemistry, 19(9), 587-593.

https://doi.org/10.1016/j.jnutbio.2007.08.002

Wang, T., Holt, M. V., \& Young, N. L. (2018). Early butyrate induced acetylation of histone H4 is proteoform specific and linked to methylation state. Epigenetics, 13(5), 519-535. https://doi.org/10.1080/15592294.2018.1475979

Wellen, K. E., Hatzivassiliou, G., Sachdeva, U. M., Bui, T. V., Cross, J. R., \& Thompson, C. B. (2009). ATP-Citrate Lyase Links Cellular Metabolism to Histone Acetylation. Science, 324(5930).

Xiong, Y., Miyamoto, N., Shibata, K., Valasek, M. A., Motoike, T., Kedzierski, R. M., \& Yanagisawa, M. (2004). Short-chain fatty acids stimulate leptin production in adipocytes through the G protein-coupled receptor GPR41. Proceedings of the National Academy of Sciences, 101(4), 1045-1050. https://doi.org/10.1073/pnas.2637002100

Yang, C., Wu, J., \& Zheng, Y. G. (2012). Function of the Active Site Lysine Autoacetylation in Tip60 Catalysis. PLOS ONE, 7(3), e32886. https://doi.org/10.1371/journal.pone.0032886 
Yuan, Z.-F., Sidoli, S., Marchione, D. M., Simithy, J., Janssen, K. A., Szurgot, M. R., \& Garcia, B. A. (2018). EpiProfile 2.0: A Computational Platform for Processing Epi-Proteomics Mass Spectrometry Data. Journal of Proteome Research, 17(7), 2533-2541. https://doi.org/10.1021/acs.jproteome.8b00133

Zgheib, C., Zouein, F. A., Chidiac, R., Kurdi, M., \& Booz, G. W. (2012). Calyculin A Reveals Serine/Threonine Phosphatase Protein Phosphatase 1 as a Regulatory Nodal Point in Canonical Signal Transducer and Activator of Transcription 3 Signaling of Human Microvascular Endothelial Cells. Journal of Interferon \& Cytokine Research, 32(2), 8794. https://doi.org/10.1089/jir.2011.0059

Zhao, L., Liu, S., Zhang, Z., Zhang, J., Jin, X., Zhang, J., Jiang, W., Li, H., \& Lin, H. (2020). Low and high concentrations of butyrate regulate fat accumulation in chicken adipocytes via different mechanisms. Adipocyte, 9(1), 120-131. https://doi.org/10.1080/21623945.2020.1738791

Zhao, S., Jang, C., Liu, J., Uehara, K., Gilbert, M., Izzo, L., Zeng, X., Trefely, S., Fernandez, S., Carrer, A., Miller, K. D., Schug, Z. T., Snyder, N. W., Gade, T. P., Titchenell, P. M., Rabinowitz, J. D., \& Wellen, K. E. (2020). Dietary fructose feeds hepatic lipogenesis via microbiota-derived acetate. Nature, 579(7800), 586-591.

https://doi.org/10.1038/s41586-020-2101-7

Zhao, S., Torres, A., Henry, R. A., Trefely, S., Wallace, M., Lee, J. V., Carrer, A., Sengupta, A., Campbell, S. L., Kuo, Y.-M., Frey, A. J., Meurs, N., Viola, J. M., Blair, I. A., Weljie, A. M., Metallo, C. M., Snyder, N. W., Andrews, A. J., \& Wellen, K. E. (2016). ATP-Citrate Lyase Controls a Glucose-to-Acetate Metabolic Switch. Cell Reports, 17(4), 1037-1052. https://doi.org/10.1016/j.celrep.2016.09.069

Zhou, Q., Dalgard, C. L., Wynder, C., \& Doughty, M. L. (2011). Histone deacetylase inhibitors SAHA and sodium butyrate block G1-to-S cell cycle progression in neurosphere 
bioRxiv preprint doi: https://doi.org/10.1101/2021.07.21.453192; this version posted July 21, 2021. The copyright holder for this preprint (which was not certified by peer review) is the author/funder, who has granted bioRxiv a license to display the preprint in perpetuity. It is made available under aCC-BY 4.0 International license.

formation by adult subventricular cells. BMC Neuroscience, 12(1), 50.

https://doi.org/10.1186/1471-2202-12-50 